\title{
CFD modeling of a vehicle exhaust laboratory sampling system: sulfur-driven nucleation and growth in diluting diesel exhaust
}

\author{
M. Olin, T. Rönkkö, and M. Dal Maso \\ Aerosol Physics Laboratory, Department of Physics, Tampere University of Technology, \\ P.O. Box 692, 33101 Tampere, Finland
}

Correspondence to: M. Olin (miska.olin@tut.fi)

Received: 12 November 2014 - Published in Atmos. Chem. Phys. Discuss.: 29 January 2015

Revised: 23 April 2015 - Accepted: 27 April 2015 - Published: 13 May 2015

\begin{abstract}
A new exhaust aerosol model CFD-TUTEAM (Tampere University of Technology Exhaust Aerosol Model for Computational Fluid Dynamics) was developed. It is based on modal aerosol dynamics modeling with log-normal assumption of particle distributions. The model has an Eulerian sub-model providing detailed spatial information within the computational domain and a computationally less expensive, but spatial-information-lacking, Lagrangian sub-model. Particle formation in a laboratory sampling system that includes a porous tube-type diluter and an aging chamber was modeled with CFD-TUTEAM. The simulation results imply that over $99 \%$ of new particles are formed in the aging chamber region because the nucleation rate remains at a high level in the aging chamber due to low dilution ratio and low nucleation exponents. The nucleation exponents for sulfuric acid in sulfuric-acid-water nucleation ranging from 0.25 to 1 appeared to fit best with measurement data, which are the same values as obtained from the slopes of the measured volatile nucleation mode number concentration vs. the measured raw exhaust sulfuric acid concentration. These nucleation exponents are very low compared to the nucleation exponents obtained from the classical nucleation theory of binary sulfuricacid-water nucleation. The values of nucleation exponent lower than unity suggest that other compounds, such as hydrocarbons, might have a significant role in the nucleation process.
\end{abstract}

\section{Introduction}

Ultrafine particles are related to adverse health effects (Dockery et al., 1993; Pope et al., 2002; Beelen et al., 2014) and various effects on climate (Arneth et al., 2009). Diesel vehicles cause a significant fraction of health-effect-inducing exposure, because they present a major contribution to ultrafine particles of urban air (Virtanen et al., 2006; Johansson et al., 2007; Pey et al., 2009) and because the sizes of the particles emitted by diesel vehicles lie in the range of high lung deposition probability (Alföldy et al., 2009; Rissler et al., 2012).

Fuel combustion generates solid particles, such as soot, ash, core (Rönkkö et al., 2007), and nanosized carbonaceous particles (Sgro et al., 2008). In addition to solid particles, liquid particles are also formed. Unlike solid particles, liquid particles are formed after the combustion process during exhaust cooling (Kittelson, 1998). In the case of a vehicle, this occurs when the exhaust is released from the tailpipe. Liquid particles are smaller than soot particles and they are formed through nucleation process; thus, they are frequently called nucleation particles. Strictly speaking, the nucleation process by definition involves an energy barrier, and it has been shown that particle formation can be a barrierless process also (Vehkamäki and Riipinen, 2012). For simplicity, we call the particle formation process in this article "nucleation" whether it involves an energy barrier or not.

The particle size distribution controls aerosol deposition to the respiratory system and its behavior in the atmosphere. Modeling studies can provide information on vehicle exhaust particle formation and evolution in the atmosphere. To model particle concentration and the size of nucleation mode, the actual nucleation rate needs to be known. In addition, modeling of vehicle exhaust particle formation can also provide 
insight on nucleation and particle formation processes in more dilute environments. The detailed nucleation mechanism controlling particle formation in vehicle exhaust is currently unknown. Studies have shown that nucleation particles contain at least water, sulfuric acid, and hydrocarbons (Kittelson, 1998; Tobias et al., 2001; Sakurai et al., 2003; Schneider et al., 2005); therefore, it is likely that these could be involved in the nucleation process. Sulfuric acid vapor (also called "gaseous sulfuric acid" in literature) concentration in diesel exhaust (Rönkkö et al., 2013), fuel sulfur content (Maricq et al., 2002; Vogt et al., 2003; Vaaraslahti et al., 2005; Kittelson et al., 2008), lubricating oil sulfur content (Vaaraslahti et al., 2005; Kittelson et al., 2008), and exhaust after-treatment (Vogt et al., 2003) has been found to correlate with nucleation particle concentration, at least in the cases when the test vehicle has been equipped with an oxidative exhaust after-treatment. As a counterexample, no correlation between fuel sulfur content and particle number concentration can be seen from the results of Rönkkö et al. (2007).

Particle formation and dilution in vehicle exhaust and in laboratory sampling systems have been studied by several authors (Vouitsis et al., 2005; Lemmetty et al., 2006, 2008; Arnold et al., 2012; Li and Huang, 2012; Pirjola et al., 2015) in temporal coordinates. However, because particle formation in diluting vehicle emission involves strong gradients in temperature and the concentrations of the compounds involved, full understanding of the particle formation process also requires information in spatial dimensions, usually done by using a computational fluid dynamics (CFD) approach. For vehicle exhaust plumes, modeling efforts to elucidate this situation have recently been undertaken (Uhrner et al., 2007; Albriet et al., 2010; Liu et al., 2011; Wang and Zhang, 2012; Huang et al., 2014). These efforts, however, have focused on real-world dilution situations for which boundary conditions are difficult to obtain. Controlled observations of vehicle emissions are usually performed in laboratory conditions involving diluting sampling systems. CFD modeling of particle formation in a perforated tube diluter (its operating principle corresponds to a porous tube diluter (PTD) used in exhaust laboratory measurements) with dibutyl phthalate (DBP) has been performed by Pyykönen et al. (2007). To our knowledge, no CFD modeling studies involving realistic vehicle exhaust in realistic emission sampling situations have been performed.

In this paper, an exhaust aerosol model for application in CFD modeling of realistic vehicle exhaust and its applicability to study particle formation involving sulfuric acid in diesel exhaust using previously published data (Arnold et al., 2012; Rönkkö et al., 2013) are presented. Two versions of the model code, an Eulerian and a Lagrangian model, are presented. The Eulerian model can provide the spatial information inside the sampling system, but the Lagrangian model can be used with lower computational cost due to a lower dimensionality, but it lacks spatial information. The Eulerian model is used to examine the spatial distribution of particle formation and growth in the modeled experimental setup; the findings in light of different possible nucleation mechanisms through the dependence of the formation rate on the sulfuric acid concentration are studied. In addition, model results enabled the study of relative rates of different aerosol dynamics processes, such as coagulation and deposition, inside the sampling setup, which provides valuable information for future studies of vehicle emissions. Finally, because vehicle emission studies are used as input for modeling studies of atmospheric aerosol loading, the spatial information gained from our model gives insight into the applicability of emission studies for such upscaling purposes.

\section{Model description}

\subsection{Fluid dynamics model}

The CFD code used was a commercially available software ANSYS FLUENT 14.0. It can be used to solve, e.g., flow, mass, heat, and radiation transfer problems. It is based on a finite volume method (ANSYS, 2011) in which the computational domain is divided into a finite amount of cells. Governing equations of the flow are solved in every computational cell iteratively until sufficient convergence is reached. In this study, the governing equations are continuity, momentum, energy, turbulence, gas species, and aerosol scalars transport equations.

\subsection{Aerosol dynamics model CFD-TUTEAM (Tampere University of Technology Exhaust Aerosol Model for Computational Fluid Dynamics)}

The aerosol dynamics model CFD-TUTEAM is based on the former aerosol model TUTEAM (Lemmetty et al., 2008). CFD-TUTEAM represents aerosol distributions modally (Whitby and McMurry, 1997), i.e., the total distribution is divided into log-normally distributed modes of different particle sizes. A single-component mode $j$ is modeled by three variables, which are number $M_{j, 0}$, surface area $M_{j, 2 / 3}$, and mass $M_{j, 1}$ moment concentrations of the distribution. The concentration of a $k$ th moment of a mode $j$ has a governing equation (Whitby and McMurry, 1997)

$$
\begin{aligned}
\frac{\partial M_{j, k}}{\partial t} & =-\nabla \cdot\left(M_{j, k} \boldsymbol{u}\right)+\nabla \cdot\left(\rho_{\mathrm{f}} \bar{D}_{j, k, \text { eff }} \nabla \frac{M_{j, k}}{\rho_{\mathrm{f}}}\right) \\
& +\operatorname{nucl}_{j, k}+\operatorname{cond}_{j, k}+\operatorname{coag}_{j, k},
\end{aligned}
$$

where $\boldsymbol{u}$ is the flow velocity vector, $\rho_{\mathrm{f}}$ is the fluid density, $\bar{D}_{j, k, \text { eff }}$ is $k$ th moment-weighted average of $D_{\text {eff }}$, and the last terms represent source terms for nucleation, condensation, and coagulation, which are described in Sect. 2.2.3. However, in a multi-component aerosol system, the mass moments are further divided into moments, $M_{j, 1, i}$, where $i$ denotes a liquid component in the particle. 
The parameters of log-normal distributions (number concentration $N_{j}$, count median diameter $\mathrm{CMD}_{j}$ and geometric $\mathrm{SD} \mathrm{GSD}_{j}$ ) can be computed from the three moments according to Whitby and McMurry (1997).

CFD-TUTEAM consists of an Eulerian- and a Lagrangian-type sub-model. In the Eulerian model, the moment variables are connected to the CFD model by solving the scalar transport equations of type Eq. (1). The Lagrangian model uses cooling and dilution profiles obtained from the CFD model as inputs.

\subsubsection{Eulerian model}

The Eulerian aerosol model is two-way coupled with the CFD model: (1) the properties on the fluid side affect on the transport equation of the particle variables Eq. (1); (2) nucleation and condensation on the aerosol side affect on the transport equation of gas species as negative source terms.

Temperature, gas species concentrations, and particle distribution parameters in hot exhaust and cold dilution air are the boundary conditions that are used at the domain boundaries in the corresponding inlets. Computation of the CFD model and the Eulerian aerosol model provide the solution for flow and particle parameters inside the simulation domain and their values at the outlet.

The simulation domain is a two-dimensional axial symmetric geometry. The measurement setup to be modeled had no time dependence in the results in a short timescale, which allows a computationally more efficient steady-state simulation.

\subsubsection{Lagrangian model}

The Lagrangian aerosol model is a Matlab code in which the differential equations Eq. (1), with the exception of the first two terms (convection and diffusion), are solved numerically. Temperature and gas species concentration data from different path lines of the fluid obtained from the Eulerian CFD model are used as time series inputs for the Lagrangian model. The Lagrangian aerosol model is only one-way coupled with the CFD model: gas-to-particle conversion (nucleation and condensation) has no effect on the fluid side. The one-way coupling approximation is sufficient as gas-toparticle conversion decreases the mass concentrations of sulfuric acid, water, and hydrocarbon vapors, in maximum, by 4,1 , and $1 \%$, respectively, in the whole simulation domain of the Eulerian simulations. The one-way coupling also enables the modeling of particle dynamics with a higher resolution compared to fluid modeling.

The path lines contain no spatial information in the Lagrangian model, but temporal information exist. However, the Lagrangian model can also be considered a steady-state simulation, because the inputs are obtained from a steadystate CFD simulation. Due to fewer dimensions in the Lagrangian model compared to the Eulerian model, a very high temporal resolution can be simulated with the same computational cost. The output from the Eulerian model is actually interpolated to a higher resolution to match the input required for the Lagrangian model. However, the Lagrangian model has, in principle, the same resolution for temperature and gas species concentrations as the Eulerian model because the solution has been calculated using the lower resolution. The higher resolution is, however, used for particle dynamics in the Lagrangian model. Therefore, comparing the particle distribution results from both models provides information on the sufficiency of the spatial resolution of the Eulerian model. A high resolution is required for particle dynamics processing due to the non-linear and exponential nature of the equations controlling particle dynamics.

Running the Lagrangian aerosol model provides the particle distribution parameters as a function of time for different path lines. The values at the ends of the different path lines can be averaged to get information on the particle parameters at the outlet.

\subsubsection{Aerosol dynamics}

Modeled aerosol processes are shown in Fig. 2, and different terms of Eq. (1) are explained next.

"Nucleation" is a key process controlling particle number concentration in diluting exhaust particle formation, which is generally considered sulfur-driven, more specifically sulfuric-acid-driven. Binary homogeneous nucleation (BHN) of water and sulfuric acid has been used as a nucleation mechanism in previous diesel exhaust modeling studies (Lemmetty et al., 2006, 2008; Uhrner et al., 2007; Albriet et al., 2010; Liu et al., 2011; Li and Huang, 2012; Wang and Zhang, 2012; Huang et al., 2014). The nucleation rate $J$ of BHN can be derived from classical thermodynamics, and the theory for this is called classical nucleation theory (CNT). Following the first nucleation theorem (Kashchiev, 1982), the nucleation exponent for nucleating species $i$ is defined as:

$n_{i}=\frac{\partial \log J}{\partial \log C_{i}}$,

where $C_{i}$ is the concentration of species $i$. According to $\mathrm{CNT}$, the nucleation exponent for sulfuric acid vapor (subscript: sa) $n_{\text {sa }}$ in vehicle exhaust is about 5 or more. In activation-type nucleation (Kulmala et al., 2006), $n_{\mathrm{sa}}=1$, and in kinetic nucleation (McMurry and Friedlander, 1979), $n_{\mathrm{sa}}=2$. Nucleation exponents 1 and 2 are found to fit to atmospheric measurement results better than the values from CNT in some studies (Sihto et al., 2009), but higher than 2 have also been observed (Wang et al., 2011; Herrmann et al., 2014). However, nucleation exponents have not yet been widely explored in connection with diesel exhaust. The nucleation mechanism in diesel exhaust can differ from the mechanism in atmosphere due to different gas concentration and temperature ranges. According to our simulations 
with CNT nucleation (Olin et al., 2014), nucleation rate obtained from CNT needs to be corrected with a relatively large factor that decreases exponentially (correction factor $\left.\propto\left[\mathrm{H}_{2} \mathrm{SO}_{4}\right]^{-6.6}\right)$ with increasing sulfuric acid concentration (Fig. 1). This result suggests that CNT may overestimate $n_{\mathrm{sa}}$ with a value of 6.6. Therefore, $n_{\mathrm{sa}}$ in diesel exhaust could be very low. Low nucleation exponents indicate there may be other species, such as organic compounds, that also take part in the nucleation process. Paasonen et al. (2010) have modeled different nucleation mechanisms, including organic nucleation mechanisms, for background atmospheric conditions and have observed that they correlate with measurement data better than sulfur-driven nucleation in some cases. Mathis et al. (2004a) have experimentally determined some organic compounds being capable of initiating and increasing or decreasing (depending on the functional groups) nucleation mode particle concentration emitted by a diesel engine.

However, the actual nucleation rate, which is the rate of the formation of new stable molecule clusters (Vehkamäki and Riipinen, 2012), was not able to be measured directly before the launch of, e.g., Airmodus PSM (Vanhanen et al., 2011), due to the small sizes of the clusters. The measurable quantity is the concentration of particles that are large enough for measurement devices, of which the observed nucleation rate can be estimated, from which the observed nucleation exponent can be calculated but not the actual one.

In atmospheric modeling studies, activation- and kinetictype nucleation rates have been used in the following forms (Sihto et al., 2009; Paasonen et al., 2010):

$J_{\text {act }}=A\left[\mathrm{H}_{2} \mathrm{SO}_{4}\right]$

$J_{\text {kin }}=K\left[\mathrm{H}_{2} \mathrm{SO}_{4}\right]^{2}$,

where $A$ and $K$ are activation and kinetic coefficients, respectively. The coefficients $A$ and $K$ are currently empirical constants fitted from experimental data in atmospheric modeling studies. Constant coefficients can be satisfactory approximations in atmospheric nucleation experiments, where temperature $T$ and relative humidity $\mathrm{RH}$ remain nearly constants. In contrast, $T$ and RH in vehicle exhaust are highly variable during the dilution and cooling process. Laboratory (Mathis et al., 2004b) and on-road studies (Rönkkö et al., 2006) of diesel exhaust particle emissions suggest that $T$ and RH affect the nucleation particle concentration; thus, $T$ and $\mathrm{RH}$ are involved in determining the nucleation rate. Therefore, constant coefficients cannot be used in modeling particle formation in vehicle exhaust.

The nucleation term in Eq. (1) is only related to the volatile nucleation mode (subscript: vol) and for different moments it is

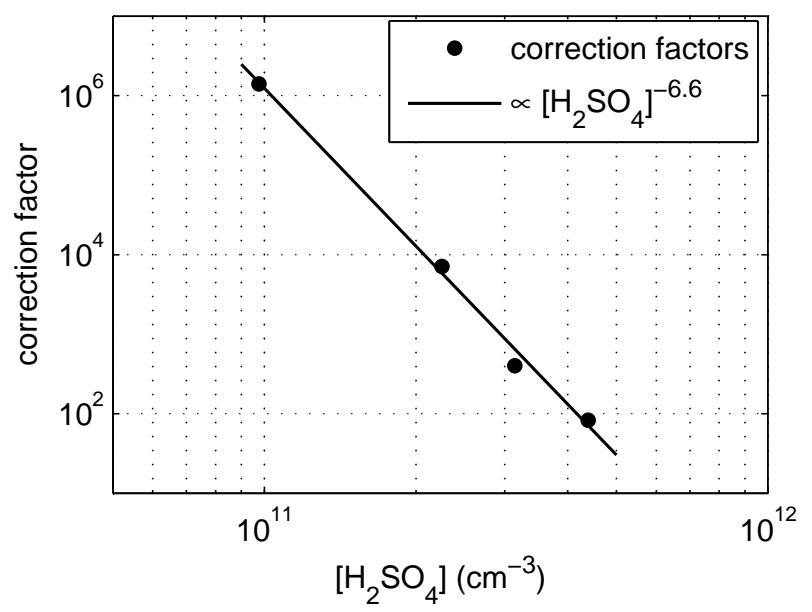

Figure 1. Correction factors for nucleation rate obtained from CNT as a function of raw exhaust sulfuric acid vapor concentration. Figure adapted from Olin et al. (2014).

$\operatorname{nucl}_{\mathrm{vol}, 0}=J$,

$\operatorname{nucl}_{\mathrm{vol}, 2 / 3}=J m^{*^{2 / 3}}$,

nucl $_{\mathrm{vol}, 1, i}=J m_{i}^{*}$,

where $m^{*}$ is the mass of the cluster formed by nucleation and $m_{i}^{*}$ the mass of component $i$ in the cluster. The nucleation rate $J$ depends on the theory used. In this study, the following nucleation scheme is used:

$J=\frac{k_{n_{\mathrm{sa}}, n_{\mathrm{w}}}}{p_{\mathrm{sa}}{ }^{\circ}(T)}\left[\mathrm{H}_{2} \mathrm{SO}_{4}\right]^{n_{\mathrm{sa}}}\left[\mathrm{H}_{2} \mathrm{O}\right]^{n_{\mathrm{w}}}$,

where $k_{n_{\mathrm{sa}}, n_{\mathrm{w}}}$ is a proportionality constant and $p_{\mathrm{sa}}{ }^{\circ}$ is the saturation vapor pressure of sulfuric acid that can be found from Kulmala and Laaksonen (1990). This scheme was selected because it is the simplest form of a nucleation scheme where the dependencies of sulfuric acid and water vapors and temperature are included. In this form, the roles of $T$ and $\mathrm{RH}$ have been included into nucleation rate by an ad hoc formulation. The temperature dependency has been included through $p_{\mathrm{sa}}{ }^{\circ}$ due to the exponential temperature dependency of $p_{\mathrm{sa}}{ }^{\circ}$, which has been found to be the case also for experimentally determined nucleation rates (Wölk and Strey, 2001; Iland et al., 2004). $p_{\mathrm{sa}}{ }^{\circ}$ is in the denominator because increasing temperature has a decreasing effect on nucleation rate. The dependency of the nucleation rate on RH is included through the water vapor concentration and the nucleation exponent of it $\left(n_{\mathrm{w}}\right)$ in the same manner as for sulfuric acid. In the case of constant $T$ and RH, the nucleation rate Eq. (6) reduces to a form of Eq. (3) if the nucleation exponent is $n_{\mathrm{sa}}=1$.

"Condensation" in the model is assumed to occur by sulfuric acid, water, and hydrocarbon vapors. The condensation term for sulfuric acid is 
$\operatorname{cond}_{j, 1, \mathrm{sa}}=\int_{-\infty}^{\infty} \frac{\partial m_{\mathrm{p}, j, \mathrm{sa}}}{\partial t} \frac{\mathrm{d} N}{\mathrm{~d} \ln d_{\mathrm{p}}} \mathrm{d} \ln d_{\mathrm{p}}$

where $\frac{\partial m_{\mathrm{p}, j, \mathrm{sa}}}{\partial t}$ is the mass growth rate of a single particle in mode $j$ of diameter $d_{\mathrm{p}}$ by sulfuric acid, described in Appendix $\mathrm{A}$, and $\frac{\mathrm{d} N}{\mathrm{~d} \ln d_{\mathrm{p}}}$ is the density function of the log-normal distribution. Because water condensation and evaporation are very fast processes for small particles in low RH (Wilck, 1998), modeling them would require a very dense computational grid. Therefore, the water content in the equilibrium state of particles is computed following the approach of Uhrner et al. (2007) but with an additional iterative equilibrium checking procedure described in Appendix A. The condensation term for water becomes

$\operatorname{cond}_{j, 1, \mathrm{w}}=\kappa_{j} \frac{Y_{j, \mathrm{w}}^{\mathrm{eq}}}{Y_{j, \mathrm{sa}}^{\mathrm{eq}}} \operatorname{cond}_{j, 1, \mathrm{sa}}$,

where $\kappa_{j}$ is a factor for water equilibrium and $Y_{j, \mathrm{w}}^{\mathrm{eq}}$ and $Y_{j \text {,sa }}^{\mathrm{eq}}$ are the mass fractions of water and sulfuric acid in a particle that is in water equilibrium. Two immiscible liquid phases are considered in the particles: (1) solution of sulfuric acid and water and (2) a hydrocarbon mixture. The condensation term for hydrocarbons is of the form of Eq. (7) but with an additional factor $f_{\text {hc }}$ considered to be the fraction of hydrocarbons able to condense at temperature $T$. The phase interactions and the hydrocarbon fraction are described in Appendix A. Due to the decreasing temperature trend in the simulations of the sampling system, no evaporation process is included in the model.

"Coagulation" modeling is based on the model of Whitby and McMurry (1997). Intramodal coagulation of the volatile nucleation mode and intermodal coagulation from the volatile nucleation mode to other modes are modeled (Fig. 2). The modeling of intramodal coagulation of the core and soot modes and intermodal coagulation between them are neglected due to their insignificancy and irrelevancy compared to the other coagulation directions.

"Diffusion" is modeled as laminar and turbulent parts. The laminar diffusion coefficient for particles $D_{\mathrm{p}, \text { lam }}$ is expressed with the Stokes-Einstein relation (Hinds, 1999)

$D_{\mathrm{p}, \mathrm{lam}}=\frac{k_{\mathrm{B}} T C_{\mathrm{c}}\left(d_{\mathrm{p}}\right)}{3 \pi \mu_{\mathrm{f}} d_{\mathrm{p}}}$,

where $k_{\mathrm{B}}$ is the Boltzmann constant, $C_{\mathrm{c}}$ is the slip correction coefficient (Allen and Raabe, 1985), $\mu_{\mathrm{f}}$ is the dynamic viscosity of the fluid, and $d_{\mathrm{p}}$ is the particle diameter. The turbulent diffusion coefficient $D_{\mathrm{t}}$ is computed as $D_{\mathrm{t}}=v_{\mathrm{t}} / \mathrm{Sc}_{\mathrm{t}}$, where $v_{t}$ is the kinematic viscosity of the fluid and $\mathrm{Sc}_{\mathrm{t}}$ is the turbulent Schmidt number for which the default value of 0.7 is used. The effective diffusion coefficients of the gas species

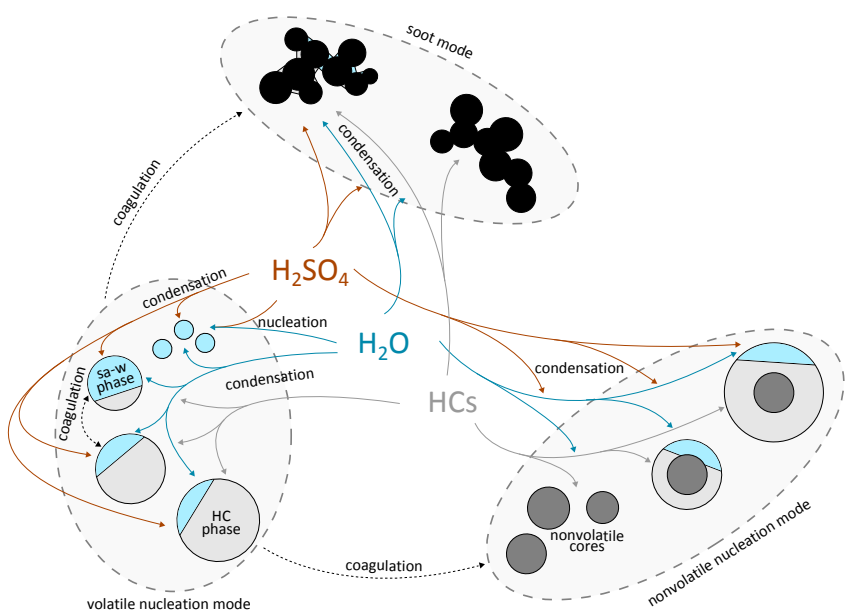

Figure 2. Modeled aerosol processes, modes, components, and phases. Detailed information on them are explained in Sect. 2.2.3 and in Appendix A.

and of particles are $D_{\phi, \text { eff }}=D_{\phi, \text { lam }}+D_{\mathrm{t}}$. In the Lagrangian model, diffusion is not modeled as in the Eulerian model due to the lack of particle concentration gradients. In the Lagrangian model, diffusion outflux from a path line is seen as dilution of gas species and particles, which is modeled using the following formula:

$M_{j, k}(t+\Delta t)=M_{j, k}(t) \frac{\mathrm{DR}(t)}{\mathrm{DR}(t+\Delta t)}$,

where DR denotes the dilution ratio. The dilution profiles are obtained from the CFD simulation. However, the diffusion influx to the path line from the surrounding areas cannot be modeled with the Lagrangian model due to lower dimensionality.

"Deposition" onto the surfaces is assumed to occur only due to diffusion, because thermophoresis was found to have only a minor role on deposition due to low thermal gradients. Deposition is modeled by setting all moments to 0 on the walls.

\section{Simulation setup}

\subsection{Simulated experiments}

To demonstrate the applicability of the CFD-TUTEAM, we applied it to a laboratory sampling system for which data have already been published by Arnold et al. (2012) and Rönkkö et al. (2013). These experiments were chosen due to the availability of simultaneous measurements of particle number concentration, size distributions, and gas-phase sulfuric acid concentrations. The experiments were performed at the engine dynamometer for a heavy-duty diesel engine. The exhaust sampling was performed with a modified partial flow sampling system (Ntziachristos et al., 2004) seen in 


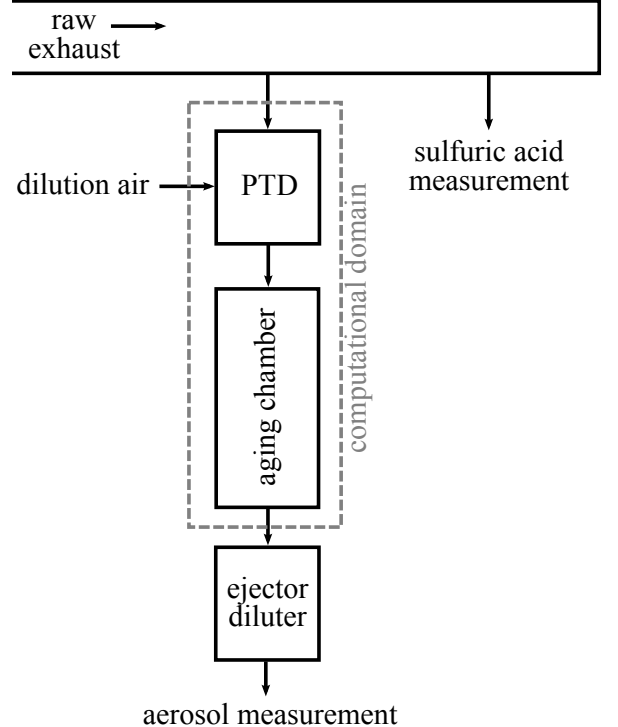

Figure 3. The part of the measurement setup relevant for the simulations. The computational domain consists of a PTD and an aging chamber only due to an approximation that the ejector diluter has a minor effect only on the particle distribution.

Fig. 3. It consists of a PTD, an aging chamber, and ejector diluters. It is used to mimic the particle formation of a realworld driving situation in a laboratory-scale measurement (Keskinen and Rönkkö, 2010).

In both measurements (Arnold et al., 2012; Rönkkö et al., 2013), sulfuric acid vapor concentration before the sampling system and particle distribution after the sampling system were measured. Both measurements were performed with the same engine with nearly the same measurement system. In the simulated measurements of Arnold et al. (2012) (indexed by A) fuel sulfur content was $6 \mathrm{ppm}$, but in the measurements of Rönkkö et al. (2013) (indexed by R) it was $36 \mathrm{ppm}$. The engine was equipped with a diesel oxidation catalyst (DOC) in both measurements, but there was a diesel particle filter (DPF) in case A and a partial diesel particle filter (pDPF) in case R. A DPF reduces the number of solid particles significantly more than a pDPF. Therefore, the main differences between the results of these two experiments were slightly higher $(\sim 50 \%$ in maximum sulfuric acid cases) sulfuric acid concentrations in the $\mathrm{R}$ case and the existence of solid particles in the $\mathrm{R}$ case.

The measurements performed with $100 \%$ engine load of the steady driving mode were simulated. All the operation parameters remained constant during the measurement points, but the sulfuric acid vapor concentration increased slowly while the time elapsed due to the unsteadiness of the storage effect of the after-treatment system (Arnold et al., 2012; Rönkkö et al., 2013). As the sulfuric acid vapor concentration was increasing, the volatile nucleation mode concentration was also increasing.

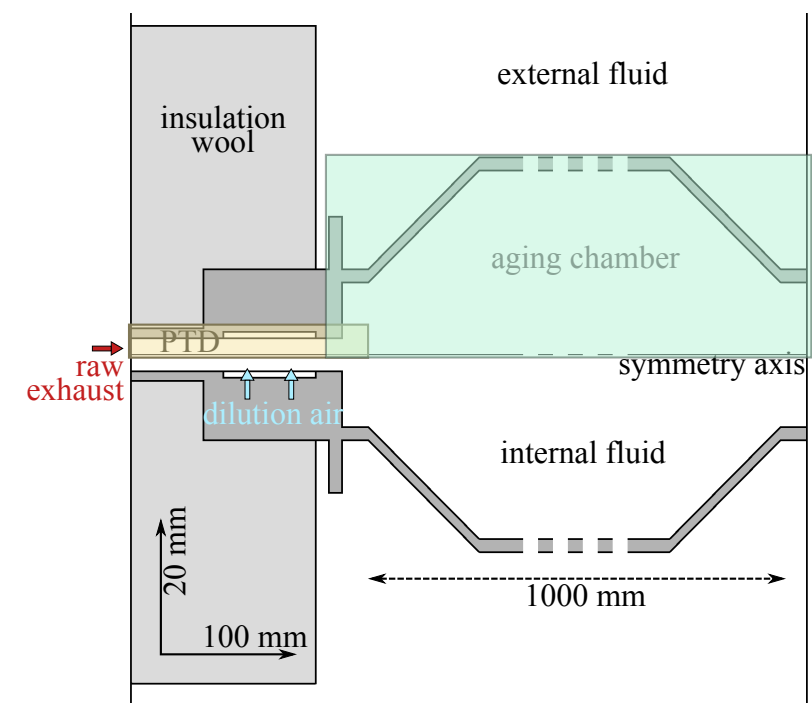

Figure 4. The computational domain. It is an axial symmetric geometry where the raw exhaust is input from the left, and the dilution air is supplied radially from a cylindrical boundary in the PTD region. The PTD is insulated but the latter part lies in stagnant external fluid. Only the ends of the aging chamber are shown, but the length of it is $1 \mathrm{~m}$ in reality. The figure is scaled vertically with a factor of 5. The yellow (PTD) and the green (aging chamber) boxes present the regions in which the contour plots are plotted in the following figures.

\subsection{Computational domain}

The sampling system seen in Fig. 3 consists of a PTD, an aging chamber, and an ejector diluter. Ejector diluters are used to stop the aerosol processes that alter the particle distribution and to obtain the conditions of the sample required for measurement devices. According to the measurements of Lyyränen et al. (2004) and Giechaskiel et al. (2009), an ejector diluter has only a minor effect on the nucleation mode particle concentration. Therefore, particle distribution at the outlet of aging chamber can be considered the measured particle distribution, though the measurements were done after the ejector diluter in reality. The computational domain for the simulations (Fig. 4) was selected to consist of the PTD and the aging chamber only.

The domain was divided into $\sim 0.5$ million computational cells, of which the major part was located inside the PTD where the smallest cells are needed due to the highest gradients. The smallest cells were $5 \mu \mathrm{m}$ in side lengths and were located in the beginning of the porous section, where the hot exhaust and the cold dilution air meet.

Internal fluid was modeled as a mixture of air, water vapor, sulfuric acid vapor, and the hydrocarbon mixture. Particle scalars were also within the internal fluid but were not connected to the fluid properties. The external fluid was modeled as air, the insulation zone as wool, and the solid zones of the PTD and the aging chamber as steel. 
Table 1. Boundary conditions for the simulations.

\begin{tabular}{|c|c|c|c|c|c|c|c|}
\hline Boundary & $\begin{array}{r}\text { Temperature } \\
\left({ }^{\circ} \mathrm{C}\right)\end{array}$ & sa mole fraction & w mole fraction & $\begin{array}{r}\text { hc mole fraction } \\
\left(\mathrm{ppmC}_{1}\right)\end{array}$ & $\begin{array}{r}\text { Flow rate } \\
(\text { SLPM) }\end{array}$ & $\begin{array}{r}N_{\text {core }} \\
\left(\mathrm{cm}^{-3}\right)\end{array}$ & $\begin{array}{r}N_{\text {soot }} \\
\left(\mathrm{cm}^{-3}\right)\end{array}$ \\
\hline Exhaust inlet & $\sim 430$ & $7 \times 10^{-11}-4 \times 10^{-8 a}$ & 0.085 & 3-8.5 (fitted) & 4.5 & $0-5 \times 10^{6}$ & $0-4 \times 10^{6}$ \\
\hline Dilution air inlet & $\sim 30$ & 0 & $\sim 0.004(10 \% \mathrm{RH})$ & 0 & 50 & 0 & 0 \\
\hline Inner walls & Coupled & Zero flux ${ }^{b}$ & $0^{c}$ or zero flux ${ }^{b}$ & $0^{\mathrm{c}}$ or zero flux ${ }^{\mathrm{b}}$ & 0 & 0 & 0 \\
\hline
\end{tabular}

${ }^{\mathrm{a}}$ Corresponds to $7 \times 10^{8}-4 \times 10^{11} \mathrm{~cm}^{-3} \cdot{ }^{\mathrm{b}}$ When saturation ratio is below unity, vapor is not depositing. ${ }^{\mathrm{c}}$ When saturation ratio is over unity, vapor is depositing.

\subsection{Boundary conditions and simulation parameters}

The boundary conditions are described in Table 1. Eight cases from Rönkkö et al. (2013) measurements and nine cases from Arnold et al. (2012) measurements with different sulfuric acid vapor mole fractions were simulated. For $\mathrm{R}$ cases, nonvolatile nucleation mode (core mode, subscript: core) and soot mode (subscript: soot) concentrations vary depending on the case. For A cases, core and soot modes were not observed, and they were therefore omitted from the simulations. Other parameters remained nearly constants in different cases.

The water vapor mole fraction in exhaust was calculated from combustion reaction stoichiometry and with a lambda value (the fraction of injected air mass compared to the air mass required for the stoichiometric combustion) of 1.54. The water vapor concentration in dilution air was obtained by assuming that dilution air RH was $10 \%$. RH was not measured, but $\mathrm{RH}=10 \%$ can be considered an upper limit, because the pressure of the compressed air (maximum RH is $100 \%$ ) used for the dilution air was 10 bar. Total hydrocarbon mole fractions (except the most volatile hydrocarbons) in the raw exhaust were set to values that produce the measured volatile nucleation mode particle sizes (the diameter of a particle with the average volume) at the outlet.

Deposition was implemented in the CFD model by setting the mole fraction for a depositing vapor at the boundary to 0 ; for non-depositing vapor, a zero flux at the boundary was implemented. A vapor was considered depositing when its saturation ratio exceeded unity near the boundary and non-depositing otherwise. For sulfuric acid vapor, saturation never exceeded unity in these simulations; hence the zero flux assumption was always used. In reality, dilution air cools the PTD; however, the cooling was not simulated because it would require the modeling of the dilution air outside the dilution air inlet boundary. This would have increased the complexity of the simulation due to the porousness of the diluter and due to the requirement for a three-dimensional simulation. We estimate that exhaust temperatures in the sampling pipe of the PTD would be lower and the dilution air temperatures higher near the boundary where the hot exhaust and cold dilution air are mixed. Hence, sulfuric acid vapor might condense on the cooled inner walls of the sampling pipe of the PTD. A saturation ratio of more than unity for hydrocarbons was calculated as a fraction of condensing hydrocarbons $f_{\text {hc }}$ described in Appendix A. All particles were modeled as depositing; thus, all moments were set to 0 on the walls.

For the volatile nucleation mode, $\mathrm{GSD}_{\mathrm{vol}}$ was varied between 1 and 2 to ensure it remaining in a reasonable range. Nucleation produces a monodisperse particle distribution, for which GSD is 1 when a constant cluster size is used. The measured values of $\mathrm{GSD}_{\mathrm{vol}}$ after the aging chamber were in the range of between 1.2 and 1.3. For the core and soot modes, constant values $\mathrm{GSD}_{\text {core }}=\sim 1.13$ and $\mathrm{GSD}_{\text {soot }}=$ 2.16 were used, corresponding to measured values. Hence, the surface moments for the core and soot modes could be omitted from the model. The core mode was initially a solid particle $\left(\mathrm{CMD}_{\text {core }}=10 \mathrm{~nm}\right)$ distribution, onto which vapors could condense and which are coagulated with volatile nucleation mode particles. The soot mode was modeled as a distribution of spherical particles with a constant $\mathrm{CMD}_{\text {soot }}$ of $49 \mathrm{~nm}$, which is the measured CMD of the mobility diameter of soot particles. The reasoning behind using a constant value was due to the assumption, based on measurements, that soot particles do not grow by condensation, but instead vapors condense into the empty spaces of the fractal particles (Lemmetty et al., 2008). Therefore, the mobility diameter remains constant, but the effective density increases. The value of $\rho_{\text {soot }}=380 \mathrm{~kg} \mathrm{~m}^{-3}$ was used as the effective density of a dry soot particle (Virtanen et al., 2002), assuming $49 \mathrm{~nm}$ particle with the fractal dimension of 2.5 and the primary particle diameter of $5 \mathrm{~nm}$. The validity of the assumption was tested by calculating the mobility diameter in the case where condensation is most dominant: if all the empty spaces of the fractal particles were filled with the condensing vapors and the coagulation from the volatile nucleation mode were taken into account, $\mathrm{CMD}_{\text {soot }}$ would increase to the value of about $60 \mathrm{~nm}$ in maximum. Therefore, the assumption that $\mathrm{CMD}_{\text {soot }}$ remains as the value of $49 \mathrm{~nm}$ could be a valid approximation.

Due to steady-state simulations, all governing equations were Reynolds-averaged, i.e., time-averaged. The averaging of the momentum transport equations causes additional terms, called Reynolds stresses, to appear. Turbulence models are used to model the Reynolds stresses, but the calibration of the turbulence models has been done with experimental data, and the calibration may not be suitable in cases 
with different geometries, fluid mixture, and boundary conditions. In this case, shear-stress-transport- $k-\omega$ with low-Re correction (ANSYS, 2011) was used as a turbulence model. It produced the most reliable results of the available turbulence models using Reynolds stresses based on the pressure drop in the porous section. The modeled turbulence levels have, however, a high influence on the results, mainly on the deposition rates: an overestimated turbulence level will overestimate deposition rates and the output particle concentrations will, therefore, be underestimated. Particle concentration measurements in both boundaries of the simulation domain would have provided advantageous information on validating the turbulence model for this case, but that kind of measurement has not yet been done. Enhanced turbulence models, such as large eddy simulation or direct numerical simulation, could produce more reliable results, but the computational cost of them is significantly higher compared to Reynolds stress models.

All cases were simulated with two nucleation exponents for sulfuric acid vapor: $n_{\mathrm{sa}}=0.25$ and $n_{\mathrm{sa}}=1$. Relatively low nucleation exponents were chosen due to our previous findings (Olin et al., 2014), implying that the nucleation exponents obtained from CNT are too high. The nucleation exponent for water vapor $n_{\mathrm{w}}$ was assumed to be unity in all cases due to the lack of detailed information specifying otherwise. Thus, the nucleation rates used were the following:

$$
\begin{aligned}
& J=\frac{5.01 \times 10^{-15} \mathrm{Pacm}^{0.75} \mathrm{~s}^{-1}}{p_{\mathrm{sa}}{ }^{\circ}(T)}\left[\mathrm{H}_{2} \mathrm{SO}_{4}\right]^{0.25}\left[\mathrm{H}_{2} \mathrm{O}\right], \\
& J=\frac{7.63 \times 10^{-23} \mathrm{Pacm}^{3} \mathrm{~s}^{-1}}{p_{\mathrm{sa}^{\circ}}{ }^{\circ}(T)}\left[\mathrm{H}_{2} \mathrm{SO}_{4}\right]\left[\mathrm{H}_{2} \mathrm{O}\right],
\end{aligned}
$$

where the units are $\mathrm{cm}^{-3} \mathrm{~s}^{-1}, \mathrm{~Pa}$, and $\mathrm{cm}^{-3}$ for nucleation rate, vapor pressure, and vapor concentrations, respectively. The proportionality constants were chosen by fitting the simulated particle concentrations with the measured ones. According to the first nucleation theorem (Kashchiev, 1982), the composition of the critical cluster is connected to the nucleation exponents. However, the composition of newly formed particles did not follow the first nucleation theorem in this case, because, firstly, nucleation exponents lower than unity would lead to a cluster containing an indiscrete amount of molecules. Secondly, the critical cluster composition and nucleation exponents have recently been found to be unconnected (Kupiainen-Määttä et al., 2014). Therefore, we chose to define the newly formed particle as a particle with a diameter of $1.5 \mathrm{~nm}$, which is a relevant size of a particle from which atmospheric aerosol formation starts (Kulmala et al., 2007). However, the atmospherically relevant size may not be simply transferred to the clearly different conditions (such as temperature and vapor concentrations) prevailing in vehicle exhaust, but it is used here due to a lack of detailed information on that. A particle of the estimated size would need to contain 15 sulfuric acid and 20 water molecules to remain in water equilibrium in temperature of $100^{\circ} \mathrm{C}$ and $\mathrm{RH}$ of $10 \%$.

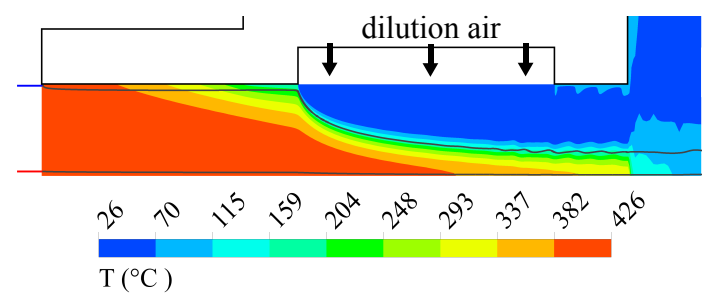

Figure 5. Temperature in the PTD region. The gray lines represent the path lines used in the Lagrangian simulation. Blue and red lines in the beginning of the path lines are the color coding of them. The figure is scaled vertically with a factor of 10 .

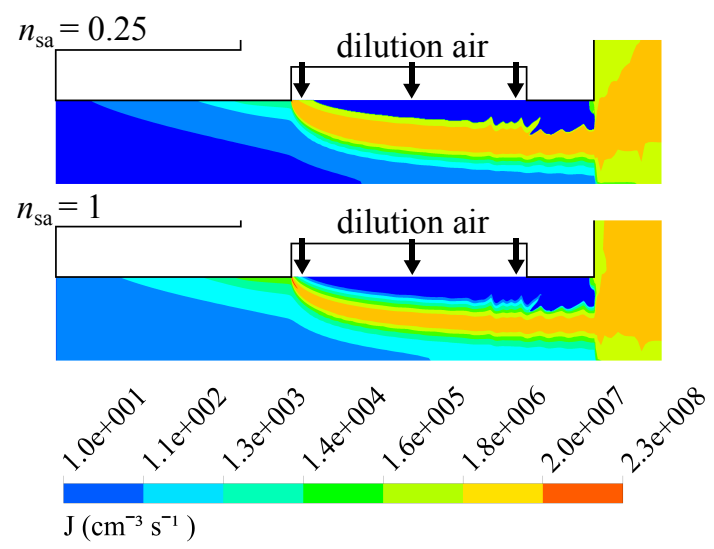

Figure 6. Nucleation rate in the PTD region when there is $\left[\mathrm{H}_{2} \mathrm{SO}_{4}\right]=1.47 \times 10^{11} \mathrm{~cm}^{-3}$ in raw exhaust of $\mathrm{R}$ case with different nucleation exponents. The figure is scaled vertically with a factor of 10 .

Hence, the cluster formed by nucleation had the following masses of the components:

$m_{\mathrm{sa}}^{*}=15 \times \frac{98.079 \mathrm{~g} \mathrm{~mol}^{-1}}{N_{\mathrm{A}}}$
$m_{\mathrm{w}}^{*}=20 \times \frac{18.015 \mathrm{~g} \mathrm{~mol}^{-1}}{N_{\mathrm{A}}}$,

where $N_{\mathrm{A}}$ is the Avogadro constant.

\section{Results and discussion}

\subsection{Spatial examination of particle formation in the sampling system}

Figures 5 and 6 show that nucleation begins at the boundary where the hot exhaust and the cold dilution air meet. With a higher nucleation exponent $n_{\text {sa }}$, the nucleation rate reaches higher maximum values, but it also diminishes faster. This can be seen clearer from Fig. 7, where the nucleation rate with the nucleation exponent of unity also has a higher maximum on the axis and decreases faster compared to the nucleation exponent of 0.25 . Due to low nucleation exponents and 


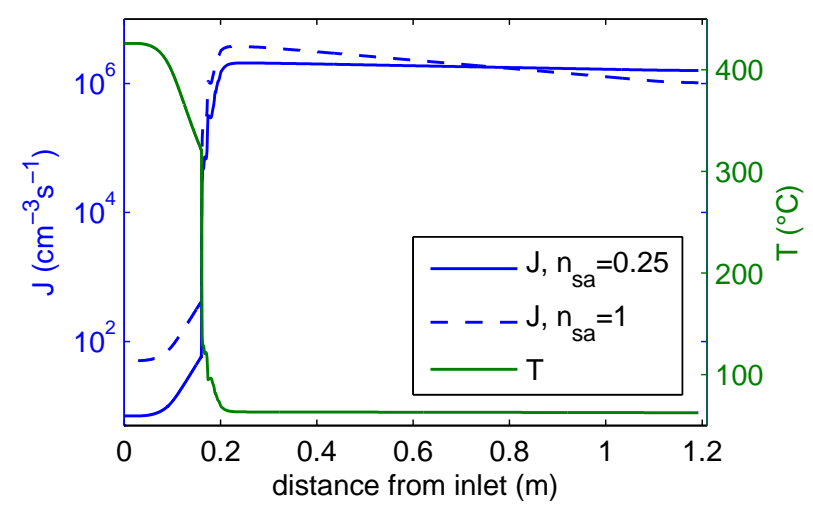

Figure 7. Temperature and nucleation rate at the axis when there is $\left[\mathrm{H}_{2} \mathrm{SO}_{4}\right]=1.47 \times 10^{11} \mathrm{~cm}^{-3}$ in raw exhaust of $\mathrm{R}$ case with different nucleation exponents.

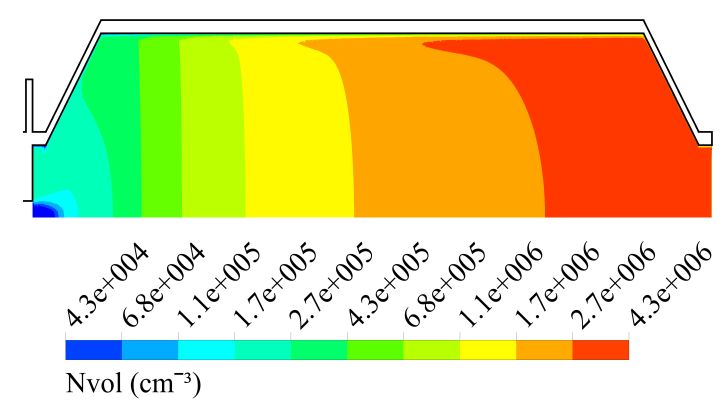

Figure 8. The volatile nucleation mode concentration in the aging chamber region when there is $\left[\mathrm{H}_{2} \mathrm{SO}_{4}\right]=1.47 \times 10^{11} \mathrm{~cm}^{-3}$ in raw exhaust of R case with $n_{\mathrm{sa}}=0.25$. The figure is scaled vertically with a factor of 10 .

a low dilution ratio, $\mathrm{DR}=12$, the nucleation rate remains high in the aging chamber where the dilution process has already finished. According to the simulations, over $99 \%$ of the particles were formed in the aging chamber in all cases, which can be seen from Fig. 8 in which the volatile nucleation mode concentration increases approximately 2 orders of magnitude during the aging chamber.

In $\mathrm{R}$ cases, the volatile nucleation mode number concentration was decreased by $3-9 \%$ due to coagulation, depending on the case. Cases with the smallest particles had the highest coagulation losses due to higher coagulation coefficients. Coagulation to the soot mode contributed over $70 \%$ of the total coagulation loss. Deposition onto the inner surfaces of the PTD and the aging chamber decreased the volatile nucleation mode concentration by $8-14 \%$, depending on the case. Cases with the smallest particles had also the highest deposition losses due to the increased diffusion coefficient. About $25 \%$ of core and soot particles were deposited. The fraction of the deposited particles was lower for the volatile nucleation mode, because the major depositing region is the expander at the beginning of the aging chamber (due to increased turbulence), where only a small fraction

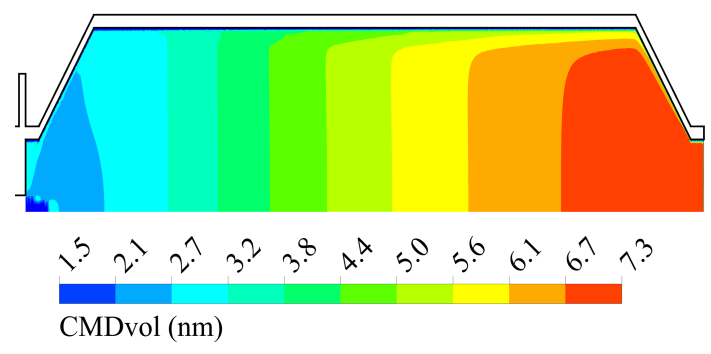

Figure 9. The volatile nucleation mode $\mathrm{CMD}$ in the aging chamber region when there is $\left[\mathrm{H}_{2} \mathrm{SO}_{4}\right]=1.47 \times 10^{11} \mathrm{~cm}^{-3}$ in raw exhaust of $\mathrm{R}$ case with $n_{\mathrm{sa}}=0.25$. The figure is scaled vertically with a factor of 10 .

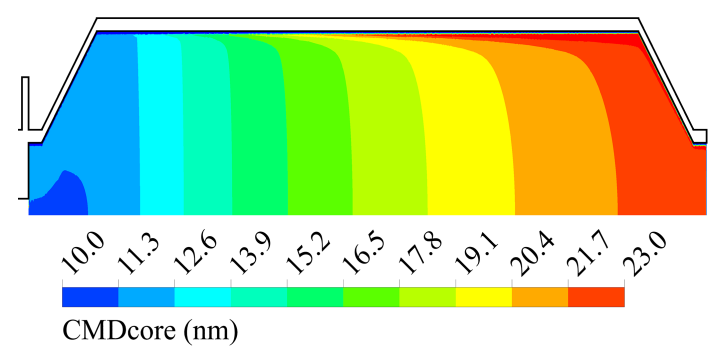

Figure 10. The core mode CMD in the aging chamber region when there is $\left[\mathrm{H}_{2} \mathrm{SO}_{4}\right]=1.47 \times 10^{11} \mathrm{~cm}^{-3}$ in raw exhaust of $\mathrm{R}$ case with $n_{\mathrm{sa}}=0.25$. The figure is scaled vertically with a factor of 10 .

of all volatile nucleation mode particles had been formed already.

Figures 9 and 10 present CMD for the volatile and nonvolatile nucleation modes in the aging chamber region. Values of $\mathrm{CMD}_{\mathrm{vol}}$ are about $1 \mathrm{~nm}$ lower than measured (Fig. 11), because modeled $\mathrm{GSD}_{\mathrm{vol}}$ values are higher (around 1.5) than measured (below 1.3). The error is probably caused by the simultaneous nucleation and condensation processes, which both affect the volatile nucleation mode distribution that is modeled as log-normal in this model. In reality, the distribution will not remain log-normal when nucleation and condensation occur simultaneously.

Modeled values of $\mathrm{CMD}_{\text {core }}$ are about $4 \mathrm{~nm}$ higher than measured. This could be due to overestimated dry solid core particle size or overestimated condensation to the nonvolatile nucleation mode. The particle distribution was not, however, measured after the aging chamber but after the ejector diluter, which was omitted from the model. Because particle sizes can, in principle, also increase in the ejector diluter, the measured $\mathrm{CMD}_{\text {core }}$ values might be slightly lower if the measurement was done before the ejector diluter. In that case, the measured $\mathrm{CMD}_{\mathrm{vol}}$ values would be decreased more than $\mathrm{CMD}_{\text {core }}$ values due to smaller particle size because of the inversely proportionality of the growth rate to the particle size. Therefore, modeled values for the both CMD might be overestimated, and thus scaling of the hydrocarbon amount could 


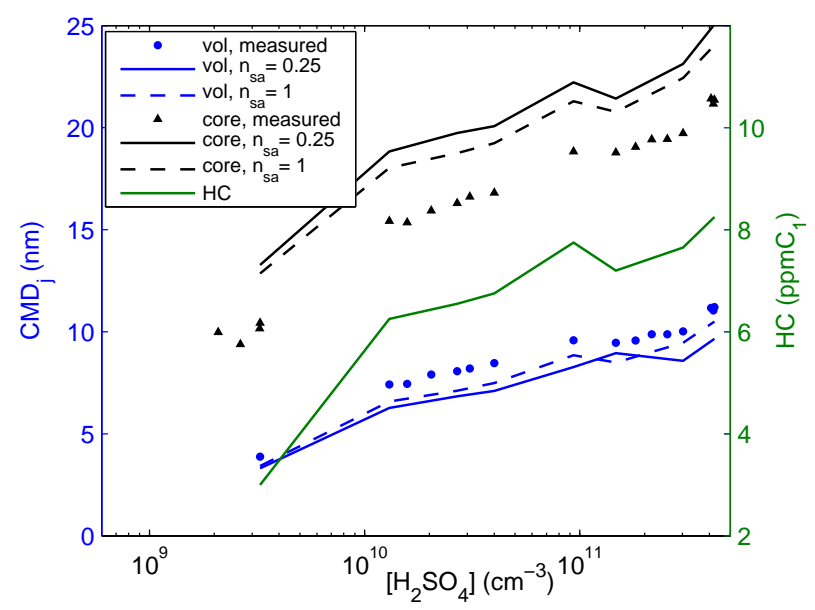

Figure 11. Measured and simulated $\mathrm{CMD}_{\mathrm{vol}}$ and $\mathrm{CMD}_{\text {core }}$ and hydrocarbon vapor amount in raw exhaust as a function of raw exhaust sulfuric acid vapor concentration in R cases. Measurement data are obtained from Rönkkö et al. (2013).

reduce the discrepancy between the modeled and the measured values.

The required hydrocarbon vapor amount is also shown in Fig. 11, from which it can be seen that an increased amount of hydrocarbon vapors was required with increasing sulfuric acid vapor concentration. This corresponds with the observation of Arnold et al. (2012): the amount of acidic vapors other than sulfuric acid correlates with the amount of sulfuric acid vapor. These acidic vapors are mainly organic vapors that have lower saturation vapor pressures compared to alkanes. Due to increased amount of low-volatile hydrocarbon vapors, the fraction of condensing hydrocarbon vapors would be increased; however, because the change of the composition of hydrocarbon mixture was not modeled, higher total hydrocarbon vapor amount was required. For A cases, a constant value of 3 ppmC $_{1}$ was used for hydrocarbon vapor amount, which produced $\mathrm{CMD}_{\mathrm{vol}}$ values between 4.8 and $5.2 \mathrm{~nm}$.

In A cases with $n_{\mathrm{sa}}=1$, only $0.5-4 \%$ of sulfuric acid vapor condensed onto the particle phase (Table 2), but in $\mathrm{R}$ cases with $n_{\mathrm{sa}}=0.25$ about $80 \%$ condensed. The difference is caused by the condensation sinks of solid particles, mainly due to the soot mode. Table 3 shows the composition of the liquid-phase compounds present in the particles, which are in agreement with the results of Pirjola et al. (2015) with the exception of the water content, which is approximately the half of the water content in the results of Pirjola et al. (2015). Hydrocarbons dominate the particle mass in the cases of lower raw exhaust sulfuric acid vapor concentrations. Table 3 also shows the maximum saturation vapor pressures of the hydrocarbons that are condensed onto the particle phase. The values correspond to low-volatile or semi-volatile organic compounds.

In reality, the shape of the region of highest nucleation rates would be different and probably transferred towards the
Table 2. Modeled proportions of sulfuric acid existing in different modes and remaining in the gas phase (\%) at the end of the aging chamber.

\begin{tabular}{lrr}
\hline Mode & $\mathrm{A}, n_{\mathrm{sa}}=1$ & $\mathrm{R}, n_{\mathrm{sa}}=0.25$ \\
\hline Vol & $0.5-4$ & $0.2-4$ \\
Soot & - & $72-74$ \\
Core & - & $1.3-4.5$ \\
Gas & $96-99.5$ & $19-22$ \\
\hline
\end{tabular}

inner wall of the sampling pipe of the PTD due to the cooling of exhaust gas by dilution air, which was not modeled. DBP nucleation simulations of Pyykönen et al. (2007) show that nucleation occurs in two regions: (1) right before the perforated section and (2) during the perforated section. If nucleation exponents are higher in reality, nucleation rate will diminish steeply in the PTD region; therefore, the major part of nucleation would occur in the PTD region. This could be examined by measuring particle concentrations inside the aging chamber or with aging chambers of different lengths. When the major part of nucleation occurs in the aging chamber, it is not obvious that the nucleation process will be quenched inside the secondary dilution. The position of nucleation region is also dependent on the effects of $T$ and RH, but they cannot be observed from these simulations. Further investigations in which $T$ and RH are varied and particle concentrations measured are required to examine these effects.

\subsection{Comparison between Eulerian and Lagrangian models}

A simulation performed by the Eulerian model of A case with raw exhaust sulfuric acid vapor concentration of $4.6 \times$ $10^{10} \mathrm{~cm}^{-3}$ and with the nucleation exponent $n_{\mathrm{sa}}=1$ was modeled with the Lagrangian model as well. The simulations were done for two path lines shown in Fig. 7. Temperature, gas species concentrations, and particle dilution profiles as a function of time were exported from the Eulerian CFD model on the path lines. The blue path begins near the inner wall of the sampling tube and the red path near the axis. Due to cylindrical symmetry, the blue path has a higher relevance on the output particle flux compared to the red path. Both lines have a total residence time of about $1.6 \mathrm{~s}$. The time domain was divided into $10^{6}$ time steps, resulting in a much higher resolution compared to the Eulerian simulation, in which the paths pass through 6000-8000 computational cells.

Figure 12 shows the nucleation rates and the particle concentrations along the path lines. The nucleation rate on the blue path develops slower than on the red path. That is because the blue path travels near the wall, and thus the velocity is lower due to friction. To reach the mixing region $21 \mathrm{~ms}$ is required, which is a longer time than for the red path $(7 \mathrm{~ms})$. In spatial coordinates, the nucleation rate on the blue path 
Table 3. Particle liquid part composition (mass \%) and the maximum saturation vapor pressures of hydrocarbons at the end of the aging chamber.

\begin{tabular}{lrrr|rrr}
\hline & \multicolumn{3}{c}{$\mathrm{A}, n_{\mathrm{sa}}=1$} & \multicolumn{3}{c}{$\mathrm{R}, n_{\mathrm{sa}}=0.25$} \\
Mode & $\mathrm{sa}$ & $\mathrm{w}$ & $\mathrm{hc}$ & $\mathrm{sa}$ & $\mathrm{w}$ & $\mathrm{hc}$ \\
\hline Vol & $2.4-14$ & $0.5-8$ & $77-97$ & $0.6-9.4$ & $0.14-6.2$ & $84-99$ \\
Soot & - & - & - & $0.6-16$ & $0.17-4.7$ & $79-99$ \\
Core & - & - & - & $0.4-11$ & $0.62-7.3$ & $82-99$ \\
\hline$p_{\mathrm{hc}}{ }^{\circ}(298 \mathrm{~K})$ & $<5 \times 10^{-7} \mathrm{~Pa}$ & & $<5 \times 10^{-6}-<2 \times 10^{-5} \mathrm{~Pa}$ \\
\hline
\end{tabular}
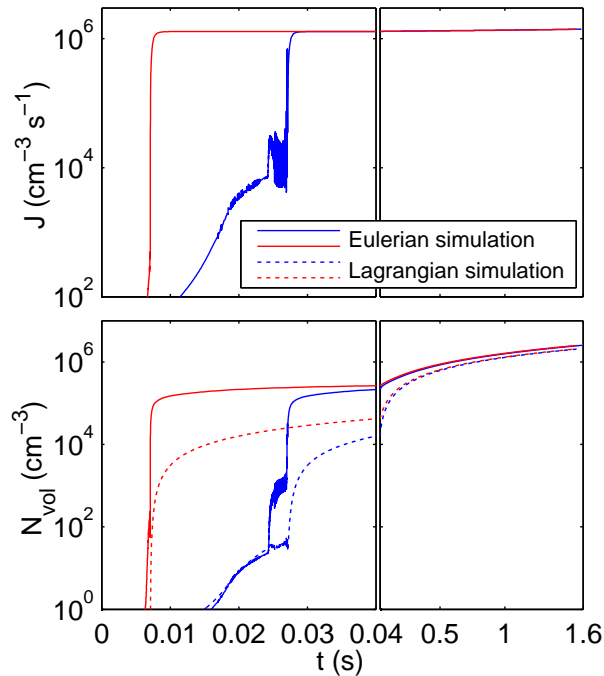

Figure 12. Nucleation rate and particle concentration as a function of time on the path lines. Nucleation rate profiles are the same in both simulations. Note the different timescales; the left plots show the very beginning of the curves as zoomed.

develops closer to the start, because it is nearer to the boundary where the hot exhaust and the cold dilution air meet, and the nucleation rate has the highest values. For the times when the path lines are inside the mixing region, some fluctuations in the nucleation rate and in the particle concentration are seen, especially on the blue path. The fluctuations are caused by transition from the laminar exhaust flow to a turbulent flow as the dilution air accelerates the flow. The fluctuation of variables can be seen also in Figs. 5 and 6 at the end of the porous section.

Comparing the particle concentrations between the Eulerian and the Lagrangian simulations, it can be observed that the concentrations in the Eulerian simulations are higher in the beginning. That is caused by the diffusion influx of the particles from the surrounding areas of a path, which cannot be modeled with the Lagrangian model but is modeled in the Eulerian model. The region where the particle concentration jumps rapidly to a high level is the expander region of the aging chamber. The diffusion influx to the paths in that region can be seen in Fig. 13, which shows the particle

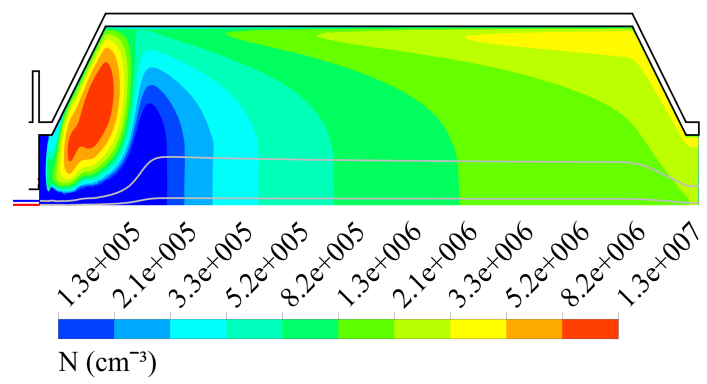

Figure 13. Particle concentration in the aging chamber region when there is $\left[\mathrm{H}_{2} \mathrm{SO}_{4}\right]=4.6 \times 10^{10} \mathrm{~cm}^{-3}$ in raw exhaust of A case with $n_{\mathrm{sa}}=1$ and when turbulent diffusion for particles is neglected. The path lines are also shown. The figure is scaled vertically with a factor of 10 .

concentration in the case where turbulent diffusion has been omitted. Omitting turbulent diffusion shows that a high particle concentration is formed in the expander due to a lower flow velocity in that section, which corresponds to a higher residence time. Because the Lagrangian model cannot model the diffusion influx from the high concentration area, the particle concentration remains lower in the model. When turbulent diffusion is modeled, high turbulence in the expander region transfers particles in all directions, which is seen as flattened particle concentration fields as seen in Fig. 8.

The concentrations at the ends of all the paths are, however, almost the same, except for $20 \%$ lower values in the Lagrangian simulation. The concentrations develop nearly to the same values because the major part of the nucleation occurs in the aging chamber where the paths experience almost the same nucleation rates.

It can be seen from Fig. 14 that some fluctuations exist in CMD and GSD values in the Eulerian simulation as in the case of nucleation rate and particle concentration. The same time delay of the values on the blue path as for the nucleation rate can also be seen for CMD and GSD values. The jumps to higher values of CMD and GSD in the Eulerian simulation are also caused by the diffusion influx from the expander region. Figure 15 presents CMD for the case of no turbulent diffusion. Due to a higher residence time in the expander region, particles grow larger; hence, a flow of larger particles by diffusion from the expander region to the path line area 


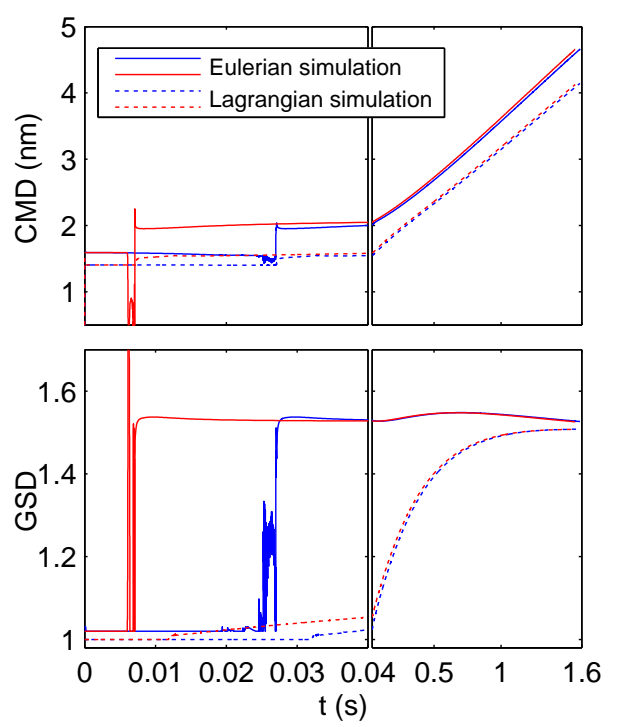

Figure 14. $\mathrm{CMD}_{\mathrm{vol}}$ and $\mathrm{GSD}_{\mathrm{vol}}$ as a function of time on the path lines. Note the different timescales.

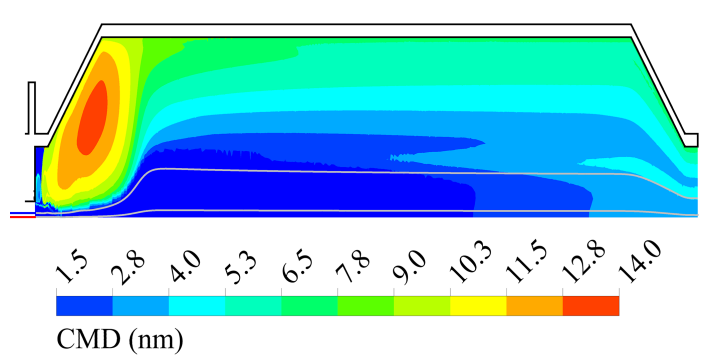

Figure 15. $\mathrm{CMD}$ in the aging chamber region when there is $\left[\mathrm{H}_{2} \mathrm{SO}_{4}\right]=4.6 \times 10^{10} \mathrm{~cm}^{-3}$ in raw exhaust of A case with $n_{\mathrm{sa}}=1$ and when turbulent diffusion for particles is neglected. The path lines are also shown. The figure is scaled vertically with a factor of 10.

occurs. Adding larger particles rapidly to the initial particle distribution formed by nucleation causes rapidly increasing CMD and GSD values. At the end, all GSD values approach nearly the same value, but CMD values appear to be about $0.5 \mathrm{~nm}$ lower in the Lagrangian simulation during the whole time domain.

Although the behavior of the Eulerian model during the fluctuating flow is not very smooth, the model is capable of approaching realistic values after that region. The fluctuation behavior can probably be smoothed by increasing the spatial resolution in that region. However, the values at the inlet and the outlet are of the main interest in this study; therefore, as the modeled outlet values for both models are approximately the same, the spatial resolution may be sufficient.

The Lagrangian model appears to produce almost equal results compared to the Eulerian model, when the output particle distribution is of interest only, despite the path line chosen for the simulation. However, in the inner areas of the sam- pling system, the Lagrangian model may produce unrealistic results if diffusion fluxes have strong effects on the particle distribution, which is especially seen in a turbulent flow. The Lagrangian model can be executed with very high time resolution without being computationally expensive. However, it requires cooling and dilution profiles obtained from the CFD model, if proper results are required. Additionally, the coupling of the fluid species with the aerosol dynamics is required to be modeled when the aerosol processes are limited by the vapor concentrations, not by time. Conversely, the Eulerian model can produce more detailed spatial information compared to the Lagrangian model, and the diffusion is also included in simulations. However, it is computationally more expensive and, therefore, the spatial resolution may remain too low to be able to produce realistic results when the same computational effort as for the Lagrangian model is considered.

\subsection{Dependence of volatile nucleation mode concentration on sulfuric acid vapor concentration}

It can be seen from Fig. 16 that the nucleation exponent $n_{\mathrm{sa}}=0.25$ fits better for $\mathrm{R}$ cases and the nucleation exponent $n_{\mathrm{sa}}=1$ better for $\mathrm{A}$ cases. The nucleation exponent 0.25 could also fit to A cases equally well in the sulfuric acid vapor concentration range between $2 \times 10^{10}$ and $3 \times 10^{11} \mathrm{~cm}^{-3}$. For $\mathrm{R}$ cases, there is also one measurement point with the lowest vapor concentration that fits well with the nucleation exponent 1.

However, particle concentrations in A cases may have been underestimated because of very low particle sizes $(\mathrm{CMD} \approx 4 \mathrm{~nm})$ for which detection efficiency for particle measurement devices is low. The effect of the detection efficiency was tested by multiplying the modeled particle distributions by the detection efficiency curve for the particle counter TSI CPC 3025 used in the measurements. The detection efficiency curve is defined by Mordas et al. (2008) for the same CPC model but for silver particles. The calculated detected particle number concentration is shown in Fig. 16 with gray lines. This decreased the particle concentrations and increased the slopes of the particle concentration very slightly compared to the modeled total particle concentrations. The increase of the slopes is obviously not enough for the nucleation exponent 0.25 to fit in all A cases. However, detailed particle size data from A measurements are not available, but they range between 4 and $5.5 \mathrm{~nm}$ (Arnold et al., 2012). Additionally, particle losses inside the particle measurement setup and devices increase with decreasing particle size, which can affect the slopes also.

The nucleation exponent $n_{\mathrm{sa}}$ can be estimated directly from the measurement data through the slope of $N_{\mathrm{vol}}$ vs. $\left[\mathrm{H}_{2} \mathrm{SO}_{4}\right]$, which are also 0.25 and 1 . It is not always possible to estimate the nucleation exponent in this manner because particle number concentration is dependent not only on nucleation rate but on other aerosol processes too. Con- 


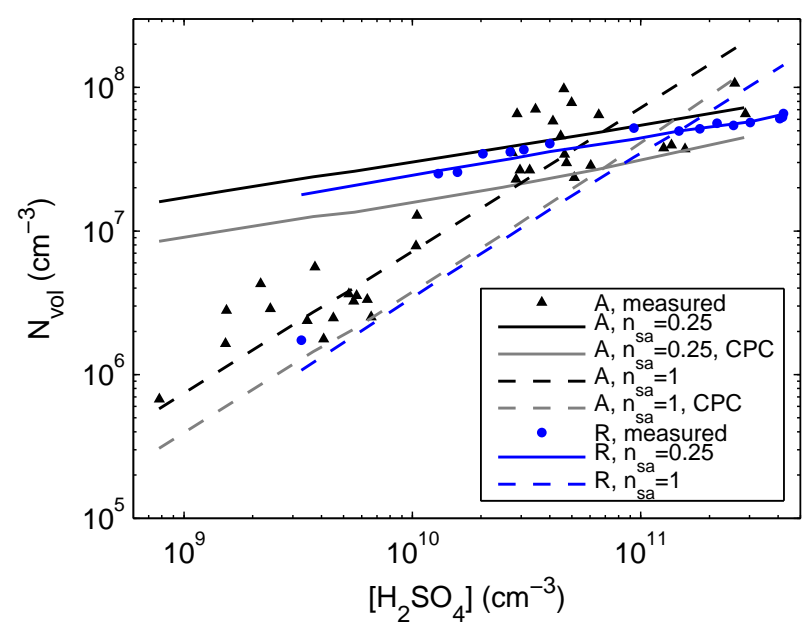

Figure 16. The measured and simulated volatile nucleation mode concentrations as a function of raw exhaust sulfuric acid vapor concentration. Particle concentrations are normalized to raw exhaust by dilution ratio 12. Measurement data for $\mathrm{R}$ cases are obtained from Rönkkö et al. (2013) and for A cases from Arnold et al. (2012).

densation and coagulation sinks have effects on the number concentration, especially for the case where soot particles exist, due to increased sinks. In these cases, the sinks resulting from solid particles were not sufficient to cause the slope to differ from the nucleation exponent, although about $77 \%$ of sulfuric acid vapor was condensed onto the solid particles. The effect of the sinks can be seen by comparing the particle number concentration levels in Fig. 16, where R cases have lower values compared to A cases. However, the soot particle sinks may be underestimated, because soot particles were modeled as spherical particles which have different surface areas compared to fractal particles.

For our cases, the nucleation exponents $n_{\mathrm{sa}}$ between 0.25 and 1 seem to produce the best results. Due to low nucleation exponents, especially when they are below unity when the nucleated cluster would have less than one sulfuric acid molecule according to the first nucleation theorem, it is probable that there are other compounds accounting in the nucleation process. Such other compounds could be, e.g., lowvolatile hydrocarbon vapors because they are also found in the particles. More realistic nucleation exponents may be obtained if a separate nucleation mechanism for hydrocarbon nucleation is modeled, e.g., the equation

$J=K_{1}\left[\mathrm{H}_{2} \mathrm{SO}_{4}\right]^{2}+K_{2}\left[\mathrm{H}_{2} \mathrm{SO}_{4}\right][\mathrm{org}]$,

where [org] is some organics accounting in nucleation, has provided the most reliable results compared to BHN, activation, or kinetic nucleation (Pirjola et al., 2015). Highly oxidized biogenic organic vapors are also found to have an effect on nucleation rate in atmospheric research of Riccobono et al. (2014). Validating attempts to model organic nucleation in vehicle exhaust would need both sulfuric acid vapor and comprehensive hydrocarbon measurements in raw exhaust with particle distribution measurements.

The reason for different nucleation exponents between $\mathrm{A}$ and $\mathrm{R}$ cases is not obvious, and further research is required to examine that. The difference could be accounted for by different sulfuric acid vapor concentration ranges, different particle size ranges, or another reason that cannot be seen from the measurements or the simulations studied here. Sulfuric acid vapor concentration range could cause the difference if the nucleation exponent were dependent on the sulfuric acid vapor concentration in a way that the nucleation exponent decreases with increasing sulfuric acid vapor concentration, which is actually seen in CNT. Different particle size range could explain the difference due to decreased counting efficiency with decreasing particle size; particle sizes were lower in A cases compared to $\mathrm{R}$ cases.

\section{Conclusions}

The CFD-TUTEAM model was used to simulate the particle formation process in a laboratory-scale diesel exhaust sampling system, consisting of a porous tube-type diluter and an aging chamber. Eulerian- and Lagrangian-type sub-models were used, and both models produced almost the same particle distributions at the outlet of the aging chamber, but it was seen that the Lagrangian model may not produce realistic results in the inner areas of the sampling system. The Lagrangian model is computationally less expensive compared to the Eulerian model; thus, it can be modeled with a higher temporal resolution with the same computational cost. However, cooling and dilution profiles from the Eulerian model are required as inputs for the Lagrangian model. Conversely, the Eulerian model produced more detailed spatial information inside the sampling system, and it includes diffusion modeling. The main advantage of the modal aerosol model is that it can be used to examine particle formation spatially with lower computational cost compared to sectional aerosol models. The drawback of it relates to the assumption that the particle distributions remain log-normal, which is not true, especially when nucleation and condensation occur simultaneously.

The highest nucleation rates were found to exist in the region where hot exhaust and cold dilution air encounter. However, due to low dilution ratio and low nucleation exponents, the nucleation rate remains high in the aging chamber where the dilution process is already finished. Hence, the major part (over $99 \%$ ) of the volatile nucleation mode particles was formed in the aging chamber. With a higher nucleation exponent, the nucleation rate would diminish more steeply in the dilution region; thus, the major part of nucleation would occur in the diluter. Additional experimental data for examining the nucleation exponent could be obtained by measuring particle concentrations inside the aging chamber or with aging chambers of different lengths. If nucleation exponents are 
low in reality, the major part of nucleation will occur in the aging chamber; therefore, it is not obvious that the nucleation process will be quenched inside the secondary dilution.

The nucleation exponents for sulfuric acid vapor in the range from 0.25 to 1 appeared to fit best with the measurement data, according to the simulations. In this range of condensation and coagulation sinks resulting from solid particles, the nucleation exponents can be estimated directly from the measurement data through the slope of the volatile nucleation mode number concentration vs. the raw exhaust sulfuric acid vapor concentration. Due to the nucleation exponents below unity, it is probable that there are other compounds, such as organics, affecting the nucleation rate. The reason for different nucleation exponents between the cases is not obvious, and further research is required to examine that.
According to the simulations, the major part of deposition occurs in the region of the expander of the aging chamber. Turbulence increases in the expander, which increases the effective diffusion coefficient; therefore, deposition rate increases. The expander had higher influence on the core and soot mode compared to the volatile nucleation mode, because the major part of the volatile nucleation mode particles was formed after the expander. 


\section{Appendix A: Detailed description of condensation modeling}

\section{A1 Mass growth rate equation}

Modeled particle diameters range from a molecule diameter to below $1 \mu \mathrm{m}$. This range participates in free-molecular, transition, and continuum regions. The Fuchs-Sutugin correction factor $\beta_{i}$ (Seinfeld and Pandis, 2006) in the growth rate equation allows smooth behavior of condensation in all the regions. Especially for hydrocarbons, the growth rate calculation requires the molecule diameter $d_{i}$ with very small particles, which is included in the equation as $\left(d_{\mathrm{p}}+d_{i}\right)$ (Lehtinen and Kulmala, 2003).

The mass growth rate of a single particle in mode $j$ by a condensing vapor $i$ becomes

$$
\begin{aligned}
\frac{\partial m_{\mathrm{p}, j, i}}{\partial t} & =\frac{2 \pi m_{i}}{k_{\mathrm{B}} T}\left(d_{\mathrm{p}}+d_{i}\right) \beta_{i}\left(D_{\mathrm{p}, \text { lam }}+D_{i, \text { lam }}\right) \\
& \times\left(p_{i}-p_{i, \mathrm{p}}\right),
\end{aligned}
$$

where $m_{i}, D_{i, \mathrm{lam}}, p_{i}$, and $p_{i, \mathrm{p}}$ are the molecule mass, diffusion coefficient, partial pressure, and vapor pressure on the particle surface of a vapor $i$, respectively. For water and sulfuric acid vapors, $p_{i, \mathrm{p}}$ is calculated by

$p_{i, \mathrm{p}}=\frac{A_{\mathrm{sa}-\mathrm{w}}}{A_{\mathrm{p}}} \Gamma_{i} K_{i} p_{i}^{\circ}$,

where $A_{\text {sa-w }}$ is the surface area of sa-w phase in a particle, and $A_{\mathrm{p}}$ is the surface area of the whole particle. $\Gamma_{i}, K_{i}$, and $p_{i}{ }^{\circ}$ are activity (Taleb et al., 1996), Kelvin factor, and saturation vapor pressure of vapor $i$. For hydrocarbon vapors, the last term of Eq. (A1) is computed as

$\left(p_{i}-p_{i, \mathrm{p}}\right)=f_{\mathrm{hc}} p_{\mathrm{hc}}$

Kelvin factor for water and sulfuric acid is calculated by

$K_{i}=\exp \left(\frac{4 \sigma_{\mathrm{sa}-\mathrm{w}} m_{i}}{k_{\mathrm{B}} T \rho_{\mathrm{sa}-\mathrm{w}} d_{\mathrm{p}}}\right)$

where $\sigma_{\text {sa-w }}$ and $\rho_{\text {sa-w }}$ are surface tension (Vehkamäki et al., 2003) and density (Vehkamäki et al., 2002) of sa-w solution.

\section{A2 Phase interactions}

Liquid parts in particles are considered two immiscible phases: sulfuric-acid-water phase (sa-w) and hydrocarbon (hc) phase. The phase with lower volume fraction is assumed to form a lens on the surface of the other phase (Ziemann and McMurry, 1998) as shown in Fig. 2. The surface area of the whole particle, $A_{\mathrm{p}}$, is considered the area onto which condensation occurs, regardless of the particle composition. However, e.g., sulfuric acid does not evaporate from a particle from the area of hc phase. Therefore, the fraction $\frac{A_{\mathrm{sa}-\mathrm{w}}}{A_{\mathrm{p}}}$ is used in Eq. (A2). The fraction can be obtained from geometrical calculations, and the following fitting functions are used for it:

$\frac{A_{\text {minor }}}{A_{\mathrm{p}}}=0.237\left(\frac{V_{\text {minor }}}{V_{\mathrm{p}}}\right)+0.539\left(\frac{V_{\text {minor }}}{V_{\mathrm{p}}}\right)^{1 / 2}$

for the volatile nucleation mode. Subscript minor presents the phase with the minority of the volume $V$ in the particle. For the core mode, the fraction is

$$
\begin{aligned}
\frac{A_{\text {minor }}}{A_{\mathrm{p}}} & =0.237\left[\frac{V_{\text {minor }}}{V_{\mathrm{p}}}\left(1-d^{\prime 3}\right)\right] \\
& +0.539\left[\frac{V_{\text {minor }}}{V_{\mathrm{p}}}\left(1-d^{\prime 3}\right)\right]^{1 / 2}
\end{aligned}
$$

if

$\frac{V_{\text {minor }}}{V_{\mathrm{p}}}<\frac{\left(1-d^{\prime}\right)^{2}\left(2+d^{\prime}\right)}{4\left(1-d^{\prime 3}\right)}$

and

$$
\begin{aligned}
\frac{A_{\text {minor }}}{A_{\mathrm{p}}} & =\left(0.336 d^{\prime 1.602}+0.667\right)\left(\frac{V_{\text {minor }}}{V_{\mathrm{p}}}\right) \\
& -0.168 d^{\prime 1.602}+0.167
\end{aligned}
$$

otherwise. In the equation, $d^{\prime}=\frac{d_{\text {core }}}{d_{\mathrm{p}}}$, where $d_{\text {core }}$ denotes the solid core diameter in the nonvolatile nucleation mode particle. Due to more complex geometry of soot particles, a constant value of unity, as an approximation, for the fraction is used for the soot mode.

\section{A3 Fraction of condensing hydrocarbons}

Due to a wide range of different hydrocarbons in diesel exhaust, it is not reasonable to model them all. A new method to model hydrocarbons is implemented in the model. According to Donahue et al. (2006), hydrocarbons in diesel exhaust can be partitioned to bins with different volatilities. Hydrocarbons with partial pressure higher than corresponding vapor pressure on the particle are considered the condensing hydrocarbon vapor fraction. These hydrocarbons satisfy the equation

$p_{\mathrm{hc}}>\frac{A_{\mathrm{hc}}}{A_{\mathrm{p}}} \Gamma_{\mathrm{hc}} p_{\mathrm{hc}}{ }^{\circ}(T)$,

where Kelvin factor calculation is neglected due to a wide range of the properties of different hydrocarbons. Unity is used as a value for activity of hydrocarbons $\Gamma_{\mathrm{hc}}$.

Assuming the diesel exhaust organic aerosol volatility distribution measured by May et al. (2013), with a temperature $T$ in Kelvins and partial pressure of total hydrocarbons $p_{\mathrm{hc}}$ in Pascals, the mass fraction of

$$
f_{\mathrm{hc}}\left(p_{\mathrm{hc}}, T\right)=\left[1+p_{\mathrm{hc}}^{-0.7} \exp \left(-\frac{5457}{T}+11.83\right)\right]^{-1}
$$


of hydrocarbons satisfies Eq. (A9). The volatility distribution is measured from the aerosol phase, but it is used here as the volatility distribution of the gas phase due to the lack of such a distribution. The side of the lowest volatilities of the distribution is, however, approximately equal for the gas-phase distribution too (Donahue et al., 2006). Therefore, Eq. (A10) is valid only when $f_{\mathrm{hc}} \lesssim 0.5$. In this study, $f_{\mathrm{hc}}$ is always below 0.4. Modeled hydrocarbons exclude volatile organic compounds because they are not present in the aerosol phase volatility distribution. However, during the condensation process, the hydrocarbon distribution is changed due to the assumption that condensation consumes hydrocarbon vapors with the highest saturation ratios first. Therefore, the fraction of condensable hydrocarbon vapors is decreasing during the condensation process. This is included in the model by subtracting the fraction of already condensed hydrocarbon vapors $f_{\mathrm{hc} \text {,cond }}$ from Eq. (A10), and it is defined as

$f_{\mathrm{hc}, \text { cond }}=\frac{\sum_{j} M_{j, 1, \mathrm{hc}}}{\sum_{j} M_{j, 1, \mathrm{hc}}+C_{\mathrm{hc}}}$,

where $C_{\mathrm{hc}}$ is the mass concentration of hydrocarbon mixture remaining in the gas phase.

The properties of tetracosane $\left(\mathrm{C}_{24} \mathrm{H}_{50}\right)$ are used as the properties of hydrocarbon mixture because 24 is the average carbon chain length of the alkanes in the diesel exhaust particles, according to Schauer et al. (1999). The mass fraction of condensable hydrocarbon vapors is used instead of the mole fraction because the hydrocarbon mixture is modeled as the average carbon chain and the condensation rate is modeled as mass basis.

\section{A4 Water equilibrium computation procedure}

A particle in water equilibrium is defined as a particle onto which no condensation occurs and from which no evaporation of water vapor occurs. Therefore, the following equation is satisfied:

$$
\mathrm{RH}=\frac{A_{\mathrm{sa}-\mathrm{w}}}{A_{\mathrm{p}}}\left(T, \boldsymbol{Y}^{\mathrm{eq}}\right) \Gamma_{\mathrm{w}}\left(T, \boldsymbol{Y}^{\mathrm{eq}}\right) K_{\mathrm{w}}\left(T, \boldsymbol{Y}^{\mathrm{eq}}, d_{\mathrm{p}}\right),
$$

where $\boldsymbol{Y}^{\mathrm{eq}}$ denotes the particle composition in water equilibrium.

The factor for water equilibrium $\kappa_{j}$ in Eq. (8) is altered after every iteration of CFD software until the volatile and nonvolatile nucleation mode particles in the whole computational domain are in water equilibrium. Ensuring water equilibrium is performed by checking that the particles satisfy Eq. (A12). Initially $\kappa_{j}=1$; thus, the composition $\boldsymbol{Y}^{\text {eq }}$ solved from Eq. (A12) is as an initial guess for the iterative procedure of water equilibrium.

For the Lagrangian model, water equilibrium is maintained by altering water content in the particles artificially after every time step in such a manner that Eq. (A12) is satisfied. 
Acknowledgements. This work was funded by the Maj and Tor Nessling foundation (project number 2014452), by the Finnish Funding Agency for Technology and Innovation, Tekes (TREAM project), and by Dinex Ecocat Oy, Neste Oil Oyj, AGCO Power, and $\mathrm{Ab}$ Nanol Technologies Oy.

Edited by: A. Virtanen

\section{References}

Albriet, B., Sartelet, K., Lacour, S., Carissimo, B., and Seigneur, C.: Modelling aerosol number distributions from a vehicle exhaust with an aerosol CFD model, Atmos. Environ., 44, 1126-1137, doi:10.1016/j.atmosenv.2009.11.025, 2010.

Alföldy, B., Giechaskiel, B., Hofmann, W., and Drossinos, Y.: Size-distribution dependent lung deposition of diesel exhaust particles, J. Aerosol Sci., 40, 652-663, doi:10.1016/j.jaerosci.2009.04.009, 2009.

Allen, M. and Raabe, O.: Slip correction measurements of spherical solid aerosol particles in an improved Millikan apparatus, Aerosol Sci. Tech., 4, 269-286, doi:10.1080/02786828508959055, 1985.

ANSYS: ANSYS FLUENT 14.0 software manual, Canonsburg, USA, 2011.

Arneth, A., Unger, N., Kulmala, M., and Andreae, M.: Clean the air, heat the planet?, Science, 326, 672-673, doi:10.1126/science.1181568, 2009.

Arnold, F., Pirjola, L., Rönkkö, T., Reichl, U., Schlager, H., Lähde, T., Heikkilä, J., and Keskinen, J.: First online measurements of sulfuric acid gas in modern heavy-duty diesel engine exhaust: implications for nanoparticle formation, Environ. Sci. Technol., 46, 11227-11234, doi:10.1021/es302432s, 2012.

Beelen, R., Raaschou-Nielsen, O., Stafoggia, M., Andersen, Z., Weinmayr, G., Hoffmann, B., Wolf, K., Samoli, E., Fischer, P., Nieuwenhuijsen, M., Vineis, P., Xun, W., Katsouyanni, K., Dimakopoulou, K., Oudin, A., Forsberg, B., Modig, L., Havulinna, A., Lanki, T., Turunen, A., Oftedal, B., Nystad, W., Nafstad, P., De Faire, U., Pedersen, N., Östenson, C.G., Fratiglioni, L., Penell, J., Korek, M., Pershagen, G., Eriksen, K., Overvad, K., Ellermann, T., Eeftens, M., Peeters, P., Meliefste, K., Wang, M., Bueno-De-Mesquita, B., Sugiri, D., Krämer, U., Heinrich, J., De Hoogh, K., Key, T., Peters, A., Hampel, R., Concin, H., Nagel, G., Ineichen, A., Schaffner, E., ProbstHensch, N., Künzli, N., Schindler, C., Schikowski, T., Adam, M., Phuleria, H., Vilier, A., Clavel-Chapelon, F., Declercq, C., Grioni, S., Krogh, V., Tsai, M.-Y., Ricceri, F., Sacerdote, C., Galassi, C., Migliore, E., Ranzi, A., Cesaroni, G., Badaloni, C., Forastiere, F., Tamayo, I., Amiano, P., Dorronsoro, M., Katsoulis, M., Trichopoulou, A., Brunekreef, B., and Hoek, G.: Effects of long-term exposure to air pollution on natural-cause mortality: an analysis of 22 European cohorts within the multicentre ESCAPE project, Lancet, 383, 785-795, doi:10.1016/S01406736(13)62158-3, 2014

Dockery, D., Pope III, C., Xu, X., Spengler, J., Ware, J., Fay, M., Ferris Jr., B., and Speizer, F.: An association between air pollution and mortality in six U.S. cities, New Engl. J. Med., 329, 1753-1759, doi:10.1056/NEJM199312093292401, 1993.
Donahue, N. M., Robinson, A. L., Stanier, C. O., and Pandis, S. N.: Coupled partitioning, dilution, and chemical aging of semivolatile organics, Environ. Sci. Technol., 40, 2635-2643, doi:10.1021/es052297c, 2006.

Giechaskiel, B., Ntziachristos, L., and Samaras, Z.: Effect of ejector dilutors on measurements of automotive exhaust gas aerosol size distributions, Meas. Sci. Technol., 20, 045703, doi:10.1088/0957-0233/20/4/045703, 2009.

Herrmann, E., Ding, A. J., Kerminen, V.-M., Petäjä, T., Yang, X. Q., Sun, J. N., Qi, X. M., Manninen, H., Hakala, J., Nieminen, T., Aalto, P. P., Kulmala, M., and Fu, C. B.: Aerosols and nucleation in eastern China: first insights from the new SORPES-NJU station, Atmos. Chem. Phys., 14, 2169-2183, doi:10.5194/acp14-2169-2014, 2014.

Hinds, W. C.: Aerosol Technology: Properties, Behavior, and Measurement of Airborne Particles, 2nd edn., John Wiley and Sons, Inc., Hoboken, USA, 1999.

Huang, L., Gong, S. L., Gordon, M., Liggio, J., Staebler, R., Stroud, C. A., Lu, G., Mihele, C., Brook, J. R., and Jia, C. Q.: Aerosolcomputational fluid dynamics modeling of ultrafine and black carbon particle emission, dilution, and growth near roadways, Atmos. Chem. Phys., 14, 12631-12648, doi:10.5194/acp-1412631-2014, 2014.

Iland, K., Wedekind, J., Wölk, J., Wagner, P. E., and Strey, R.: Homogeneous nucleation rates of 1-pentanol, J. Chem. Phys., 121, 12259-12264, doi:10.1063/1.1809115, 2004.

Johansson, C., Norman, M., and Gidhagen, L.: Spatial and temporal variations of $\mathrm{PM}_{10}$ and particle number concentrations in urban air, Environ. Monit. Assess., 127, 477-487, doi:10.1007/s10661006-9296-4, 2007.

Kashchiev, D.: On the relation between nucleation work, nucleus size, and nucleation rate, J. Chem. Phys., 76, 5098-5102, doi:10.1063/1.442808, 1982.

Keskinen, J. and Rönkkö, T.: Can real-world diesel exhaust particle size distribution be reproduced in the laboratory? A critical review, J. Air Waste Manage., 60, 1245-1255, doi:10.3155/10473289.60.10.1245, 2010.

Kittelson, D.: Engines and nanoparticles: a review, J. Aerosol Sci., 29, 575-588, doi:10.1016/S0021-8502(97)10037-4, 1998.

Kittelson, D., Watts, W., Johnson, J., Thorne, C., Higham, C., Payne, M., Goodier, S., Warrens, C., Preston, H., Zink, U., Pickles, D., Goersmann, C., Twigg, M., Walker, A., and Boddy, R.: Effect of fuel and lube oil sulfur on the performance of a diesel exhaust gas continuously regenerating trap, Environ. Sci. Technol., 42, 9276-9282, doi:10.1021/es703270j, 2008.

Kulmala, M. and Laaksonen, A.: Binary nucleation of watersulfuric acid system: Comparison of classical theories with different $\mathrm{H}_{2} \mathrm{SO}_{4}$ saturation vapor pressures, J. Chem. Phys., 93, 696-701, doi:10.1063/1.459519, 1990.

Kulmala, M., Lehtinen, K. E. J., and Laaksonen, A.: Cluster activation theory as an explanation of the linear dependence between formation rate of $3 \mathrm{~nm}$ particles and sulphuric acid concentration, Atmos. Chem. Phys., 6, 787-793, doi:10.5194/acp-6-787-2006, 2006.

Kulmala, M., Riipinen, I., Sipilä, M., Manninen, H. E., Petäjä, T., Junninen, H., Dal Maso, M., Mordas, G., Mirme, A., Vana, M., Hirsikko, A., Laakso, L., Harrison, R. M., Hanson, I., Leung, C., Lehtinen, K. E. J., and Kerminen, V.-M.: Toward di- 
rect measurement of atmospheric nucleation, Science, 318, 8992, doi:10.1126/science.1144124, 2007.

Kupiainen-Määttä, O., Olenius, T., Korhonen, H., Malila, J., Dal Maso, M., Lehtinen, K., and Vehkamäki, H.: Critical cluster size cannot in practice be determined by slope analysis in atmospherically relevant applications, J. Aerosol Sci., 77, 127-144, doi:10.1016/j.jaerosci.2014.07.005, 2014.

Lehtinen, K. E. J. and Kulmala, M.: A model for particle formation and growth in the atmosphere with molecular resolution in size, Atmos. Chem. Phys., 3, 251-257, doi:10.5194/acp-3-251-2003, 2003.

Lemmetty, M., Pirjola, L., Mäkelä, J., Rönkkö, T., and Keskinen, J.: Computation of maximum rate of water-sulphuric acid nucleation in diesel exhaust, J. Aerosol Sci., 37, 1596-1604, doi:10.1016/j.jaerosci.2006.04.003, 2006.

Lemmetty, M., Rönkkö, T., Virtanen, A., Keskinen, J., and Pirjola, L.: The effect of sulphur in diesel exhaust aerosol: models compared with measurements, Aerosol Sci. Tech., 42, 916-929, doi:10.1080/02786820802360682, 2008.

Li, X. and Huang, Z.: Formation and transformation of volatile nanoparticles from a diesel engine during exhaust dilution, Chinese Sci. Bull., 57, 948-954, doi:10.1007/s11434-011-4927-8, 2012.

Liu, Y. H., He, Z., and Chan, T. L.: Three-dimensional simulation of exhaust particle dispersion and concentration fields in the nearwake region of the studied ground vehicle, Aerosol Sci. Tech., 45, 1019-1030, doi:10.1080/02786826.2011.580021, 2011.

Lyyränen, J., Jokiniemi, J., Kauppinen, E. I., Backman, U., and Vesala, H.: Comparison of different dilution methods for measuring diesel particle emissions, Aerosol Sci. Tech., 38, 12-23, doi:10.1080/02786820490247579, 2004.

Maricq, M., Chase, R., Xu, N., and Laing, P.: The effects of the catalytic converter and fuel sulfur level on motor vehicle particulate matter emissions: light duty diesel vehicles, Environ. Sci. Technol., 36, 283-289, doi:10.1021/es0109621, 2002.

Mathis, U., Mohr, M., and Zenobi, R.: Effect of organic compounds on nanoparticle formation in diluted diesel exhaust, Atmos. Chem. Phys., 4, 609-620, doi:10.5194/acp-4-609-2004, 2004a.

Mathis, U., Ristimäki, J., Mohr, M., Keskinen, J., Ntziachristos, L., Samaras, Z., and Mikkanen, P.: Sampling conditions for the measurement of nucleation mode particles in the exhaust of a diesel vehicle, Aerosol Sci. Tech., 38, 1149-1160, doi:10.1080/027868290891497, 2004b.

May, A. A., Presto, A. A., Hennigan, C. J., Nguyen, N. T., Gordon, T. D., and Robinson, A. L.: Gas-particle partitioning of primary organic aerosol emissions: (2) Diesel vehicles, Environ. Sci. Technol., 47, 8288-8296, doi:10.1021/es400782j, 2013.

McMurry, P. and Friedlander, S.: New particle formation in the presence of an aerosol, Atmos. Environ., 13, 1635-1651, doi:10.1016/0004-6981(79)90322-6, 1979.

Mordas, G., Manninen, H., Petäjä, T., Aalto, P., Hämeri, K., and Kulmala, M.: On operation of the ultra-fine water-based CPC TSI 3786 and comparison with other TSI models (TSI 3776, TSI 3772, TSI 3025, TSI 3010, TSI 3007), Aerosol Sci. Tech., 42, 152-158, doi:10.1080/02786820701846252, 2008.

Ntziachristos, L., Giechaskiel, B., Pistikopoulos, P., Samaras, Z., Mathis, U., Mohr, M., Ristimäki, J., Keskinen, J., Mikkanen, P., Casati, R., Scheer, V., and Vogt, R.: Performance evaluation of a novel sampling and measurement system for exhaust particle characterization, SAE Tech. Paper Ser., 2004-01-1439, doi:10.4271/2004-01-1439, 2004.

Olin, M., Dal Maso, M., and Rönkkö, T.: Sulfur driven nucleation in diesel exhaust: simulations of a laboratory sampling system, in: Proceedings of the 18th ETH-Conference on Combustion Generated Nanoparticles, Zürich, Switzerland, 22-25 June 2014, 4546, 2014.

Paasonen, P., Nieminen, T., Asmi, E., Manninen, H. E., Petäjä, T., Plass-Dülmer, C., Flentje, H., Birmili, W., Wiedensohler, A., Hörrak, U., Metzger, A., Hamed, A., Laaksonen, A., Facchini, M. C., Kerminen, V.-M., and Kulmala, M.: On the roles of sulphuric acid and low-volatility organic vapours in the initial steps of atmospheric new particle formation, Atmos. Chem. Phys., 10, 11223-11242, doi:10.5194/acp-10-11223-2010, 2010.

Pey, J., Querol, X., Alastuey, A., Rodriguez, S., Putaud, J., and Van Dingenen, R.: Source apportionment of urban fine and ultra-fine particle number concentration in a Western Mediterranean city, Atmos. Environ., 43, 4407-4415, doi:10.1016/j.atmosenv.2009.05.024, 2009.

Pirjola, L., Karl, M., Rönkkö, T., and Arnold, F.: Model studies of volatile diesel exhaust particle formation: organic vapours involved in nucleation and growth?, Atmos. Chem. Phys. Discuss., 15, 4219-4263, doi:10.5194/acpd-15-4219-2015, 2015.

Pope, C., Burnett, R., Thun, M., Calle, E., Krewski, D., Ito, K., and Thurston, G.: Lung cancer, cardiopulmonary mortality, and longterm exposure to fine particulate air pollution, J. Amer. Med. Assoc., 287, 1132-1141, doi:10.1001/jama.287.9.1132, 2002.

Pyykönen, J., Miettinen, M., Sippula, O., Leskinen, A., Raunemaa, T., and Jokiniemi, J.: Nucleation in a perforated tube diluter, J. Aerosol Sci., 38, 172-191, doi:10.1016/j.jaerosci.2006.11.006, 2007.

Riccobono, F., Schobesberger, S., Scott, C. E., Dommen, J., Ortega, I. K., Rondo, L., Almeida, J., Amorim, A., Bianchi, F., Breitenlechner, M., David A., Downard, A., Dunne, E. M., Duplissy, J., Ehrhart, S., Flagan, R. C., Franchin, A., Hansel, A., Junninen, H., Kajos, M., Keskinen, H., Kupc, A., Kürten, A., Kvashin, A. N., Laaksonen, A., Lehtipalo, K. Makhmutov, V., Mathot, S., Nieminen, T., Onnela, A., Petäjä, T., Praplan, A. P., Santos, F. D., Schallhart, S., Seinfeld, J. H., Sipilä, M., Spracklen, D. V., Stozhkov, Y., Stratmann, F., Tomé, A., Tsagkogeorgas, G., Vaattovaara, P., Viisanen, Y., Vrtala, A., Wagner, P. E., Weingartner, E., Wex, H., Wimmer, D., Carslaw, K. S., Curtius, J., Donahue, N. M., Kirkby, J., Kulmala, M., Worsnop, D. R., and Baltensperger, U.: Oxidation Products of Biogenic Emissions Contribute to $\mathrm{Nu}$ cleation of Atmospheric Particles, Science, 344, 717-721, doi:10.1126/science.1243527, 2014.

Rissler, J., Swietlicki, E., Bengtsson, A., Boman, C., Pagels, J., Sandström, T., Blomberg, A., and Löndahl, J.: Experimental determination of deposition of diesel exhaust particles in the human respiratory tract, J. Aerosol Sci., 48, 18-33, doi:10.1016/j.jaerosci.2012.01.005, 2012.

Rönkkö, T., Virtanen, A., Vaaraslahti, K., Keskinen, J., Pirjola, L., and Lappi, M.: Effect of dilution conditions and driving parameters on nucleation mode particles in diesel exhaust: laboratory and on-road study, Atmos. Environ., 40, 2893-2901, doi:10.1016/j.atmosenv.2006.01.002, 2006. 
Rönkkö, T., Virtanen, A., Kannosto, J., Keskinen, J., Lappi, M., and Pirjola, L.: Nucleation mode particles with a nonvolatile core in the exhaust of a heavy duty diesel vehicle, Environ. Sci. Technol., 41, 6384-6389, doi:10.1021/es0705339, 2007.

Rönkkö, T., Lähde, T., Heikkilä, J., Pirjola, L., Bauschke, U., Arnold, F., Schlager, H., Rothe, D., Yli-Ojanperä, J., and Keskinen, J.: Effects of gaseous sulphuric acid on diesel exhaust nanoparticle formation and characteristics, Environ. Sci. Technol., 47, 11882-11889, doi:10.1021/es402354y, 2013.

Sakurai, H., Tobias, H., Park, K., Zarling, D., Docherty, K., Kittelson, D., McMurry, P., and Ziemann, P.: On-line measurements of diesel nanoparticle composition and volatility, Atmos. Environ., 37, 1199-1210, doi:10.1016/S1352-2310(02)01017-8, 2003.

Schauer, J., Kleeman, M., Cass, G., and Simoneit, B.: Measurement of emissions from air pollution sources. 2. C1 through C30 organic compounds from medium duty diesel trucks, Environ. Sci. Technol., 33, 1578-1587, doi:10.1021/es980081n, 1999.

Schneider, J., Hock, N., Weimer, S., Borrmann, S., Kirchner, U., Vogt, R., and Scheer, V.: Nucleation particles in diesel exhaust: composition inferred from in situ mass spectrometric analysis, Environ. Sci. Technol., 39, 6153-6161, doi:10.1021/es049427m, 2005.

Seinfeld, J. and Pandis, S.: Atmospheric Chemistry and Physics: From Air Pollution to Climate Change, 2nd edn., John Wiley and Sons, Inc., Hoboken, USA, 2006.

Sgro, L., Borghese, A., Speranza, L., Barone, A., Minutolo, P., Bruno, A., D'Anna, A., and D'Alessio, A.: Measurements of nanoparticles of organic carbon and soot in flames and vehicle exhausts, Environ. Sci. Technol., 42, 859-863, doi:10.1021/es070485s, 2008.

Sihto, S.-L., Vuollekoski, H., Leppä, J., Riipinen, I., Kerminen, V.M., Korhonen, H., Lehtinen, K. E. J., Boy, M., and Kulmala, M.: Aerosol dynamics simulations on the connection of sulphuric acid and new particle formation, Atmos. Chem. Phys., 9, 29332947, doi:10.5194/acp-9-2933-2009, 2009.

Taleb, D.-E., Ponche, J.-L., and Mirabel, P.: Vapor pressures in the ternary system water-nitric acid-sulfuric acid at low temperature: a reexamination, J. Geophys. Res.-Atmos., 101, 25967-25977, doi:10.1029/96JD02330, 1996.

Tobias, H., Beving, D., Ziemann, P., Sakurai, H., Zuk, M., McMurry, P., Zarling, D., Waytulonis, R., and Kittelson, D.: Chemical analysis of diesel engine nanoparticles using a nanoDMA/thermal desorption particle beam mass spectrometer, Environ. Sci. Technol., 35, 2233-2243, doi:10.1021/es0016654, 2001

Uhrner, U., von Löwis, S., Vehkamäki, H., Wehner, B., Bräsel, S., Hermann, M., Stratmann, F., Kulmala, M., and Wiedensohler, A.: Dilution and aerosol dynamics within a diesel car exhaust plumeCFD simulations of on-road measurement conditions, Atmos. Environ., 41, 7440-7461, doi:10.1016/j.atmosenv.2007.05.057, 2007.

Vaaraslahti, K., Keskinen, J., Giechaskiel, B., Solla, A., Murtonen, T., and Vesala, H.: Effect of lubricant on the formation of heavy-duty diesel exhaust nanoparticles, Environ. Sci. Technol., 39, 8497-8504, doi:10.1021/es0505503, 2005.
Vanhanen, J., Mikkilä, J., Lehtipalo, K., Sipilä, M., Manninen, H. E., Siivola, E., Petäjä, T., and Kulmala, M.: Particle size magnifier for nano-CN detection, Aerosol Sci. Tech., 45, 533542, doi:10.1080/02786826.2010.547889, 2011.

Vehkamäki, H. and Riipinen, I.: Thermodynamics and kinetics of atmospheric aerosol particle formation and growth, Chem. Soc. Rev., 41, 5160-5173, doi:10.1039/C2CS00002D, 2012.

Vehkamäki, H., Kulmala, M., Napari, I., Lehtinen, K., Timmreck, C., Noppel, M., and Laaksonen, A.: An improved parameterization for sulfuric acid-water nucleation rates for tropospheric and stratospheric conditions, J. Geophys. Res.-Atmos. 107, AAC 3-1-AAC 3-10, doi:10.1029/2002JD002184, 2002.

Vehkamäki, H., Kulmala, M., Lehtinen, K., and Noppel, M.: Modelling binary homogeneous nucleation of water-sulfuric acid vapours: parameterisation for high temperature emissions, Environ. Sci. Technol., 37, 3392-3398, doi:10.1021/es0263442, 2003.

Virtanen, A., Ristimäki, J., Marjamäki, M., Vaaraslahti, K., Keskinen, J., and Lappi, M.: Effective density of diesel exhaust particles as a function of size, SAE Tech. Paper Ser., 2002-01-0056, doi:10.4271/2002-01-0056, 2002.

Virtanen, A., Rönkkö, T., Kannosto, J., Ristimäki, J., Mäkelä, J. M., Keskinen, J., Pakkanen, T., Hillamo, R., Pirjola, L., and Hämeri, K.: Winter and summer time size distributions and densities of traffic-related aerosol particles at a busy highway in Helsinki, Atmos. Chem. Phys., 6, 2411-2421, doi:10.5194/acp-6-2411-2006, 2006.

Vogt, R., Scheer, V., Casati, R., and Benter, T.: On-road measurement of particle emission in the exhaust plume of a diesel passenger car, Environ. Sci. Technol., 37, 4070-4076, doi:10.1021/es0300315, 2003.

Vouitsis, E., Ntziachristos, L., and Samaras, Z.: Modelling of diesel exhaust aerosol during laboratory sampling, Atmos. Environ., 39, 1335-1345, doi:10.1016/j.atmosenv.2004.11.011, 2005.

Wang, Y. and Zhang, K.: Coupled turbulence and aerosol dynamics modeling of vehicle exhaust plumes using the CTAG model, Atmos. Environ., 59, 284-293, doi:10.1016/j.atmosenv.2012.04.062, 2012.

Wang, Z. B., Hu, M., Yue, D. L., Zheng, J., Zhang, R. Y., Wiedensohler, A., Wu, Z. J., Nieminen, T., and Boy, M.: Evaluation on the role of sulfuric acid in the mechanisms of new particle formation for Beijing case, Atmos. Chem. Phys., 11, 12663-12671, doi:10.5194/acp-11-12663-2011, 2011.

Whitby, E. and McMurry, P.: Modal aerosol dynamics modeling, Aerosol Sci. Tech., 27, 673-688, doi:10.1080/02786829708965504, 1997.

Wilck, M.: Modal modelling of multicomponent aerosols, $\mathrm{PhD}$ thesis, Universität Leipzig, Leipzig, Germany, 1998.

Wölk, J. and Strey, R.: Homogeneous nucleation of H2O and D2O in comparison: the isotope effect, J. Phys. Chem. B, 105, 1168311701, doi:10.1021/jp0115805, 2001.

Ziemann, P. J. and McMurry, P. H.: Secondary electron yield measurements as a means for probing organic films on aerosol particles, Aerosol Sci. Tech., 28, 77-90, doi:10.1080/02786829808965513, 1998. 